\title{
University of Innsbruck
}

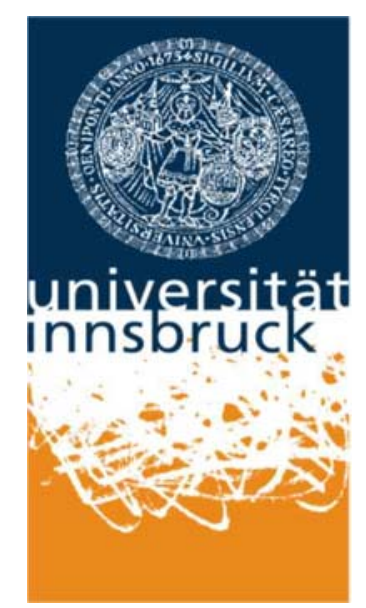

\section{Working Papers \\ in}

Economics and Statistics

\section{Testing Enforcement Strategies in the Field: Legal} Threat, Moral Appeal and Social Information

Gerlinde Fellner, Rupert Sausgruber and Christian Traxler 


\title{
Testing Enforcement Strategies in the Field: Legal Threat, Moral Appeal and Social Information*
}

\author{
Gerlinde Fellner ${ }^{\dagger} \quad$ Rupert Sausgruber ${ }^{\ddagger} \quad$ Christian Traxler ${ }^{\S}$
}

September 1, 2009

\begin{abstract}
We run a large-scale natural field experiment to evaluate alternative strategies to enforce compliance with the law. The experiment varies the text of mailings sent to potential evaders of TV license fees. We find a strong alert effect of mailings, leading to a substantial increase in compliance. Among different mailing conditions a legal threat that stresses a high detection risk has a significant and highly robust deterrent effect. Neither appealing to morals nor imparting information about others' behavior enhances compliance. However, the information condition has a positive effect in municipalities where evasion is believed to be common. Overall, the economic model of crime performs remarkably well in explaining our data.
\end{abstract}

JEL classification: K42; C93

Keywords: Field experiments; law enforcement; compliance; deterrence

${ }^{*}$ We thank Christoph Engel, Martin Hellwig, Peter Kooreman, Jo Rincke, Joel Slemrod, Adriaan Soetevent and participants in seminars at the Universities of Copenhagen, Göteborg, Michigan, Munich, Paris Nanterre, Tokyo (Waseda), Toulouse, Vienna, Zurich, as well as at the Enable Workshop (UvA, Amsterdam), the LEaF Conference (UCL, London) and the ESA Meetings in Rome, Tucson and Shanghai for helpful comments and suggestions. Carina Woodage provided excellent research assistance. The invaluable support of Annette Chemnitz, Herbert Denk and Gabriela Jerome at GIS and the financial support by the Austrian National Bank (OeNB Jubiläumsfonds, Grant No. 12301) and the Austrian Science Fund (FWF, Projects No. P17029 and No. S10307G14.) is gratefully acknowledged.

${ }^{\dagger}$ Department of Economics, Vienna University of Economics and Business; gfellner@wu.ac.at

${ }^{\ddagger}$ Department of Public Economics, University of Innsbruck; rupert.sausgruber@uibk.ac.at

${ }^{\S}$ Corresponding Autor. Max Planck Institute for Research on Collective Goods, Bonn, and CESifo, Munich; traxler@coll.mpg.de 


\section{Introduction}

The economic analysis of crime gives clear advice on how to achieve compliance with the law: it requires the detection and punishment of law violations to deter crime (Becker, 1968). Ever since Becker's seminal work, the deterrence hypothesis has been subject to controversy. On the one hand, scepticism is fueled by the difficulties in identifying deterrence. Despite substantial advances of the empirical literature (for a survey, see Levitt and Miles, 2007), there are only a few studies that solve the identification problem (e.g., Corman and Mocan, 2000; Levitt, 2002; DiTella and Schargrodsky, 2004; Drago et al., 2009). On the other hand, it has been argued that formal law enforcement explains only little of the variation in compliance (e.g., Dills et al., 2009) and that informal institutions, like social norms, might play a more important role in shaping adherence to the law. ${ }^{1}$ The question then arises whether law enforcement should be based on the classical economic approach to deterrence or whether one can draw upon different behavioral motives.

The present paper offers novel insights to this question by testing alternative enforcement strategies in a large-scale natural field experiment. In our setup, people are required by law to pay an annual fee for receiving public broadcasting. An enforcement problem exists because public broadcasting channels can be received without paying the fee. Those who deviate from the law, however, face a non-negligible detection risk and the threat of sizeable fines. The enforcement authority granted us access to a unique sample of more than 50,000 individuals who were identified as potential evaders. In cooperation with the authority, we send mailings to $95 \%$ of this sample. In addition, a $5 \%$ randomly selected subsample did not receive mailings. Mailing recipients were randomly assigned to treatment conditions that differed in the wording of the cover letter. Using the authority's standard letter as baseline, we varied the text along three dimensions: the letter may contain a legal threat, stressing a high detection risk and possible legal and financial sanctions, a moral appeal, emphasizing that compliance is a matter of fairness, and social information, highlighting the overall level of compliance. The different treatments were evaluated by comparing the mailing response to that in the baseline treatment and the

\footnotetext{
${ }^{1}$ See, among many others, Kahan (1997); Posner (2000); McAdams and Rasmusen (2007) and the conference volumes on Social Norms, Social Meaning and the Economic Analysis of Law (Journal of Legal Studies 27(3), 1998) as well as on The Legal Construction of Norms (Virginia Law Review 86(8), 2000).
} 
behavior in the no-mailing group. Our main focus is thereby on the number of evaders who quit deviating from the law and start to pay the fee.

The setup of the experiment allows us to overcome the identification problem faced by the law enforcement literature. First, and most importantly, the random treatment assignment assures that enforcement strategies are exogenous. Second, our key dependent variable - whether an evader starts to pay the fee - can neither be affected by incapacitation (Levitt, 1998; Kessler and Levitt, 1999) nor by spatial displacement effects (i.e., the displacement of criminals in response to a local increase in law enforcement; see, e.g., Jacob et al., 2007). Finally, the measurement of our dependent variable is independent of the experimental conditions. To ensure this property, the treatments did not intervene with the effectively implemented enforcement level: the legal threat just stresses elements of the current enforcement practice, but the objective sanction risk remained constant over all treatments. ${ }^{2}$ Any observed response to the threat (as well as to the other mailing treatments) must therefore be driven by changes in the mailing recipients' subjective perceptions regarding, e.g., the detection risk and the magnitude of fines. To explore this point further, we conducted a follow-up survey to the experiment which exposed participants from a different sample to the letters used in the field experiment. In this vein, we elicited the treatments' impact on different perception domains.

The paper provides two sets of results. The first concerns the effectiveness of deterrence. First of all, we find a striking impact of the mailings. In the no-mailing condition, the fraction of individuals who start to comply with the law within 50 days of the experiment is very low $(0.8 \%)$. Sending mailings increases this fraction to $7.7 \%$. Hence, there are almost ten times more cheaters who start to pay license fees in the mailing conditions. This corresponds to a net-revenue per mailing of $€ 15$. While the effect could also be attributed to a decline in transaction costs, our survey indicates that the mailings trigger a strong alert effect: receiving a mailing causes a substantial increase in the perceived detection risk. The mailings signal surveillance and thus - jointly with a transaction cost effect - create a pronounced effect on compliance behavior.

\footnotetext{
${ }^{2}$ There are several reasons why we decided not to change actual enforcement. First, the number of individuals who start paying the fee is mechanically linked to the number of detections from field enforcement. Similar to an increase in the level of police, one would have to disentangle a deterrence effect from the mere impact on the measured crime rate (Levitt, 1998). Second, as shown in Rincke and Traxler (2009), the enforcement of license fees through field inspections causes systematic spillovers on undetected cheaters. These spillovers would blur the measured treatment response to the legal threat.
} 
The comparison across the different mailing treatments identifies a strong deterrent effect of the legal threat. Compared to the baseline mailing, the threat increases the share of individuals who start complying by an additional percentage point. This effect corresponds to $15 \%$ increase in compliance. The survey reveals that the treatments' impact on behavior can be traced back to an increase in the perceived costs of noncompliance. Our evidence therefore documents that the legal threat shapes perceptions and that individuals rationally adjust their compliance behavior to these perceptions. By exploiting information on different types of mailing respondents we find further support for this conclusion. While the legal threat has a strong effect on evaders who face potentially severe sanctions in case of detection, it has no effect on types who are not exposed to an actual sanction risk. In summary, this first set of results lends strong support to the deterrence hypothesis. In our experiment, deterrent threats unambiguously work as enforcement strategies.

Our second set of results clarifies whether compliance can be enforced by moral suasion or by providing social information - i.e., without resorting to legal threats. The moral framing, which appeals to the fairness aspect of compliance, calls upon people's conscience and aims at making a specific moral concept more salient. Social psychology research suggests that the framing should increase compliance if the value judgment is shared by the recipients (Cialdini, 1998). In contrast to this conjecture, but in line with other studies in economics (Blumenthal et al., 2001; Wenzel and Taylor, 2004), we do not find an effect of the appeal. It is important to note, however, that our mailings are targeted to a specific sample of those who deviate from the law. Hence, the null-result does not imply that moral standards are irrelevant for the compliance of the overall population. As those who violate the law often develop anti-social norms (Meares et al., 2004), individuals in our sample might be more likely to disagree with the moral statement in the letter. In line with this interpretation, we observe that the appeal has a negative effect on compliance in several subsamples of the study. Our experiment therefore suggests that moral appeals are no attractive policy to enforce compliance among those who purposely deviate from the law.

Legal scholars emphasize that compliance is also driven by "the informal enforcement of social mores by acquaintances, bystanders, trading partners, and others" (Ellickson, 
1998, p. 540) - a view that is also reflected in economic research documenting the importance of informal sanctions (see, e.g., Falk et al., 2005). Norm-enforcing sanctions are thereby considered to be stronger the more people follow a norm (Elster, 1989). ${ }^{3}$ The social information treatment, which communicates the actual compliance rate of $94 \%$, may thus shape perceptions regarding the strength of informal law enforcement. Equivalently, the 'broken windows theory' (Wilson and Kelling, 1982) suggests that the provided information may change perceptions about formal law enforcement. ${ }^{4}$ By altering perceptions about both formal and informal sanctions, the social information can therefore affect compliance behavior.

In our experiment, we do not observe a significant effect of the information treatment. Consistent with the theoretical considerations, however, we find that imparting social information has significantly different effects in municipalities where evasion is believed to be common compared to municipalities where evasion is believed to be rare. In the former, the treatment has a positive, in the latter a weakly negative effect on compliance. This outcome complements existing evidence on social interaction effects in crime (e.g., Glaeser et al., 1996). Moreover, it relates to the literature on conditional cooperation in the private provison of public goods (Frey and Meier, 2004; Shang and Croson, 2007; Fischbacher and Gächter, 2009). Our study delivers a first piece of evidence on policies that build upon 'conditional compliance' with the law - i.e., individuals conditioning their compliance on the (perceived) compliance of others. At the same time, our results demonstrate the limits of applying 'belief management' as an enforcement tool (Fehr and Falk, 2002). With non-common priors, one and the same information can trigger opposing behavioral responses. Hence, even if individuals are conditionally compliant, belief management might fail to increase aggregate compliance.

Our results contribute to several strands of the literature. First and most importantly, we provide experimental field evidence for the deterrence hypothesis in a setup that avoids displacement and incapacitation effects. Second, we offer novel results on the effectiveness of alternative enforcement strategies within a given institutional framework. Our data thus allow for a direct comparison of classical and 'behavioral' approaches to law

\footnotetext{
${ }^{3}$ Supporting evidence for this relationship for the specific domain of TV license fee evasion is provided by survey evidence discussed in Traxler and Winter (2009).

${ }^{4}$ For recent contributions on the broken windows effect, see Corman and Mocan (2005); Harcourt and Ludwig (2006); Keizer et al. (2008).
} 
enforcement and identify several impediments for strategies that go 'beyond punishment' (Frey, 2009). Finally, linking the results from the experiment to our perception survey, we not only evaluate the effectiveness of different enforcement strategies but also contribute to an understanding of the causal links between policies, subjective perceptions, and behavior (Nagin, 1998; Lochner, 2007; Hjalmarsson, 2009).

In terms of methodology, the paper is closely related to field experiments in the domain of tax enforcement. ${ }^{5}$ The most prominent is the Minnesota Income Tax Compliance Experiment, where the Internal Revenue Service approached taxpayers with different mailing types (Blumenthal et al., 2001; Slemrod et al., 2001). A treatment similar to our legal threat studied the effects of communicating a high audit probability. The results were mixed. While low and middle-income taxpayers responded with a modest increase in reported income, the audit threat lead to lower reported tax liabilities from high income taxpayers (Slemrod et al., 2001). Appealing to taxpayers' conscience did not show any significant effects (Blumenthal et al., 2001). ${ }^{6}$ In an experiment with the Australian tax authorities, Wenzel and Taylor (2004) studied a number of interventions on taxpayers' property tax deductions. A deterrent letter did not have a significant effect in their study. More recently, Kleven et al. (2009) ran a large-scale experiment in collaboration with the Danish Inland Revenue. While they find that individuals update their declared income in response to audit threats, they also observe that many taxpayers reported lower taxable incomes (similar to Slemrod et al.).

One crucial aspect that distinguishes our study from all these important contributions concerns the measurement of the treatment response. Tax enforcement experiments typically rely on the evaluation of differences in reported income before and after a specific manipulation. The immense heterogeneity among taxpayers (in terms of their characteristics and the availability of different tax-minimizing strategies) renders such a comparison troublesome. In contrast, we evaluate our treatments based on a simple indicator variable - whether or not an evader starts to comply with the law. In addition, the set of possible responses to our treatments is well-defined and leaves less scope for the interpretation of

\footnotetext{
${ }^{5}$ For an overview of randomized experiments in the criminology literature, see the meta-study by Farrington and Welsh (2006).

${ }^{6}$ In a similar setup, Schwartz and Orleans (1967) found that normative appeals were slightly more effective than sanction threats. In a replication of the study, McGraw and Scholz (1991) neither found an effect of threats nor of appeals. The power of both contributions is, however, limited due to small sample sizes.
} 
our results. Finally, none of the mentioned studies addresses the role of perceptions for the link between policy manipulations and behavioral responses.

The remainder of the paper is structured as follows. Sections 2 and 3 present the institutional background and the design of the field experiment. In section 4, we discuss several hypotheses regarding the impact of our treatments. The results are analyzed in section 5. Section 6 studies complementary evidence on perceptions from a survey. The paper concludes with a discussion of our findings.

\section{Institutional Background}

A significant share of radio and television broadcasting around the world is provided by public broadcasters (the US being a notable exemption) that are mainly financed through TV and radio license fees: two thirds of all European, one half of African and Asian, and about $10 \%$ of countries in the Americas employ license fees. In Europe, the total amount of fees collected added up to roughly $€ 20$ billion in $2005 .^{7}$ A typical license fee system is in place in Austria. According to the Austrian Broadcasting License Fee Act, households must file a registration and pay license fees if they own a TV or a radio. The size of the annual fee is substantial. In 2005, it ranged from $€ 206$ to $€ 263$ (the fee varies between federal states). The amount is due per household, regardless of the number of household members, TVs and radios. ${ }^{8}$ An enforcement problem exists since public broadcasting programs can be received without paying the annual fees. ${ }^{9}$

The license fee system is managed by 'Gebühren Info Service' (henceforth GIS), a subsidiary of the Austrian Public Broadcasting Company. GIS is responsible for collecting and enforcing the license fee and takes actions to sustain compliance. To identify potential evaders, GIS compares residence data (i.e., a federal database in which everyone must enroll with her place of residence) and data from direct mailing companies with their own data on license fee registrations. If an individual lives at a certain address without having

\footnotetext{
${ }^{7}$ Own computation based on Open Society Institute (2005) and information provided by BFA - Broadcasting Fee Association (see www.broadcastingfee.com). Further information on license fees is provided by Head (1985) and Newcomb (2004). For a welfare analysis of private versus public broadcasting, see Anderson and Coate (2005).

${ }^{8}$ We use the term household in a broad sense, including apartment-sharing communities, etc. In addition to the fee that covers TV and radio, there exists a reduced fee (between $€ 60$ to $€ 76$ ) for radios only.

${ }^{9}$ As typical for Europe, most households receive TV via a simple rooftop antenna or a satellite dish. Cable companies have no information about whether a household pays the license fee for public broadcasting. These companies mind their own fees and do not exclude customers from viewing the public broadcasting channels.
} 
registered any TV or radio - and if no one else in the household pays fees - GIS sends a mailing to this person. The license Fee Act requires mailing recipients to respond and to provide correct information. Data on those who do not respond are handed over to GIS' enforcement division. This division employs field inspectors who check potential evaders at their homes (see Rincke and Traxler, 2009). In fact, detections by field inspectors are quite frequent. In 2004, door-to-door inspections resulted in a clearance rate of one third. A person who is detected evading the fee must register and licensing inspectors typically date back the registration for several months, i.e., a detected evader has to make supplementary payments. ${ }^{10}$ In addition, field inspectors may report a case to the authorities who can then impose a fine of up to $€ 2,180$. If someone does not comply with the payment duty after an official report, criminal proceedings will be initiated. Austrians seem to be aware of the possible sanctions. A national survey conducted in 2000 finds that $55 \%$ of respondents expect 'severe' or 'very severe' sanctions if they are detected evading TV license fees. ${ }^{11}$

GIS' enforcement activities are reflected in a high compliance rate: in July 2005, 94\% of all Austrian households were registered for license fees and payed a total of $€ 644$ million ( $0.3 \%$ of GDP). The $94 \%$ give a reasonable proxy for the overall compliance level, as only one percent of households own neither a TV nor a radio (ORF Medienforschung, 2006). Note, however, that compliance is in constant flux due to, e.g., changes in the household composition or de-registrations of households that move or simply state that they no longer operate any TV or radio. Thus, GIS constantly seeks to improve its enforcement practice.

\section{Experiment Design and Data}

In collaboration with GIS, we experimentally manipulated mailings that were sent to potential evaders of license fees. Following the standard procedures, a mailing contained a cover letter, an information sheet and a response form with a postpaid envelope. In

\footnotetext{
${ }^{10}$ At the time of detection past savings from evasion are sunk. The retrospective payments thus create similar incentives as a fine.

${ }^{11}$ For tax evasion via black labor market participation [absenteeism from work], the corresponding figure is $60 \%$ [38\%]. Details on this survey $(N>1000)$, which is further discussed in Traxler and Winter (2009), are available from the authors.
} 
the letter, GIS explains that - according to their data - the mailing recipient has not registered any $\mathrm{TV} /$ radio and that the recipient is required by law to clarify the facts by returning the response form within 14 days (see Appendix I for the full text of the cover letter). The information sheet listed several key paragraphs of the License Fee Act. In particular, it provided information about the payment duty, the size of the fee as well as the maximum fine that can be imposed in case one is detected evading the fee (see section 2).

\subsection{Treatments}

The experiment varied the text of the cover letter. Everything else, the response form and the information sheet, and thus the information on the possible fine, was kept the same across all treatments. We used the standard GIS letter as control and varied the text along three dimensions: we introduced a legal threat, social information, and a moral appeal. In addition, we interacted the threat with the two other dimensions, resulting in six different mailing treatments in total. Table 1 illustrates these treatments. ${ }^{12}$ Finally, we also implemented a no-mailing condition (T0). Individuals in this untreated control group did not receive a mailing.

Table 1: Mailing Treatments

\begin{tabular}{lccc}
\hline \hline & Standard Letter & Social Information & Moral Appeal \\
\hline without Legal Threat & $\begin{array}{c}\text { T1 } \\
\text { Control }\end{array}$ & T3 & T5 \\
& T2 & Tnfo & Moral \\
\hline \multirow{2}{*}{ with Legal Threat } & Threat & Threat $\times$ Info & Threat $\times$ Moral \\
\hline \hline
\end{tabular}

In the legal-threat treatments (T2, T4, and T6), the cover letter contained a paragraph that communicates a significant detection probability and emphasizes potential consequences of non-compliance (see Appendix I for details on all letters). We used the following wording:

\footnotetext{
${ }^{12}$ Our approach can be interpreted as an incomplete $2 \times 2 \times 2$-design. At the benefit of a larger number of observations in each treatment cell, we decided not to implement the interactions between the social information and the moral appeal.
} 
"If you do not respond to this letter, a staff member of GIS will contact you in order to request information from you personally. If you refuse to provide information or if there is a well-founded suspicion that you provide disinformation, GIS is obligated to order an inquiry by the responsible federal authorities. Please keep in mind that in this case you may face legal consequences and considerable costs."

In treatments T3 and T4, the letter imparted social information, i.e., information about the actual level of compliance with the law (as estimated by GIS). The relevant paragraph was formulated as follows:

"Do you actually know that almost all citizens comply with this legal duty? In fact, 94 percent - a vast majority of all households - have registered their broadcasting receivers."

Treatments T5 and T6 extended the standard cover letter by the following moral appeal:

"Those who do not conscientiously register their broadcasting receivers not only violate the law, but also harm all honest households. Hence, registering is also a matter of fairness."

\subsection{Sample and Implementation}

GIS provided us with 50,498 addresses of potential evaders. From these data we first took a 5\% random subsample and assigned it to the no-mailing group (T0). We then randomly allocated the remaining data to the six mailing treatments T1 - T6. Table 2 provides summary statistics and demonstrates that the treatment assignment was orthogonal to observable individual and municipality characteristics. ${ }^{13}$ Further descriptive statistics on the 1120 (out of 2300) Austrian municipalities covered by our sample are provided in Table A.1 in the Appendix.

There is no deliberate selection of communities into the experiment. Following standard procedures, GIS collects updated residence data alternately from different municipalities as well as new data from direct mailing companies. Our sample is based on the most recent data that were available to GIS in August 2005 and that were not used in prior mailing campaigns. Hence, there is no 'randomization bias' (Levitt and List, 2009). From these data, potential evaders were identified by GIS according to the procedures

\footnotetext{
${ }^{13}$ Kruskal Wallis tests, as well as variance analyses, confirm the null hypothesis of equality of means across treatments of all variables in table 2 .
} 
Table 2: Individual and municipality characteristics per treatment

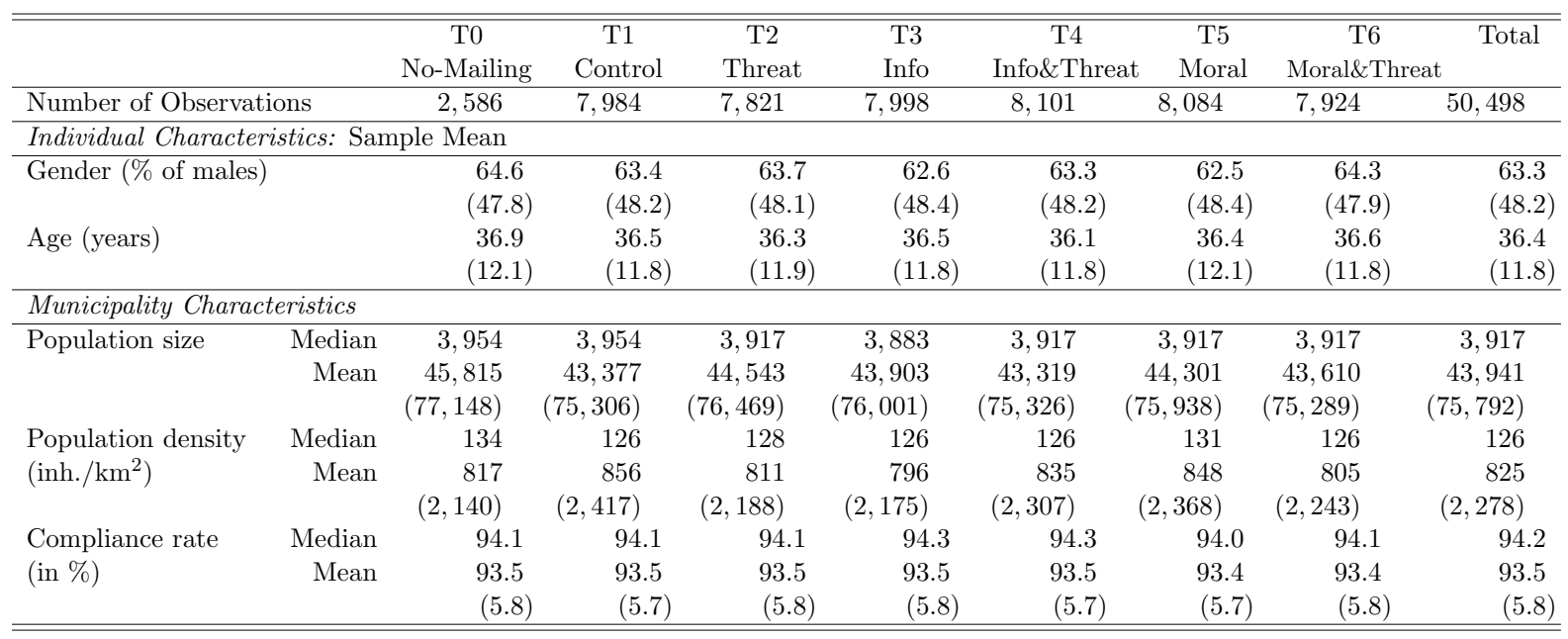

Notes: Age is only available for a subsample of 16,281 recipients. Population density is measured as the number of inhabitants per square kilometer. Similar to the overall rate, GIS approximates the local compliance rate by the share of households who are registered for license fees relative to the total number of households living in a municipality. Standard deviation is in parentheses.

described in the previous section. Thus, the final sample is not representative of the overall population. Moreover, it covers individuals beyond the subpopulation of license fee evaders.

To illustrate this point and to facilitate the following analysis, we classify the different types of individuals in the sample. First, there are evaders (A-types), individuals from households that have not registered their TVs/radios. ${ }^{14}$ Second, the sample contains individuals who comply with their payment duty or live in a household that does so $(B$ types). Nevertheless, these types are in the sample, either because of spelling errors in the residence data or because they changed their address or name (e.g., after marriage) without reporting these changes to GIS. Finally, the sample includes individuals who neither own a TV nor a radio (C-types). As we will discuss below, these different types face different response options and different incentives to respond.

The mailings were sent by GIS in two waves between September 19 and October 17, 2005. In order to avoid confounding time effects, each wave contained all treatments in equal proportions. Between September and December 2005, GIS did not change the in-

\footnotetext{
${ }^{14}$ It typically takes several months until data on newly formed households or households that recently moved appear in the residence data available to GIS. Those who have not yet registered their $\mathrm{TV} /$ radio by the time they receive a mailing can therefore be called evaders rather than procrastinators.
} 
tensity of field inspections, nor did they inform anybody about our study. The mailing recipients were not aware of participating in an experiment. Following the taxonomy by Harrison and List (2004), this feature distinguishes our study as a natural field experiment. ${ }^{15}$

Mailing responses and unsolicited registrations in the no-mailing group were measured by GIS' computer system. ${ }^{16}$ This system allowed a highly accurate measurement of behavior: it tracked responses via the reply forms that were sent along with the mailings, it recorded registrations that were made online or by phone, and it detected responses from another individual living in the same household as the recipient of the mailing (e.g., the spouse). Note further that the measurement of the experimental outcome was the same for all mailing treatments. This is an important detail as it assures that the measurement is orthogonal to the experimental conditions.

The mailing responses were classified into four categories:

(A) A new registration of a $\mathrm{TV} /$ radio.

(B) An update of contract details (name, address, etc.), or a statement that someone in the household is already paying the fee.

(C) A statement of the recipient that there is no broadcasting receiver in the household.

(D) Any response that cannot be classified into the other categories.

These response categories can be directly linked to the type classification introduced above. A-types, who are liable to pay fees, can either respond to the mailing by registering (A), by asserting that they have no TV or radio in the household $(\mathrm{C})$, or they can ignore the mailing and not respond. B-types, who are already law-abiding, can either clarify their status by a B-response or they can ignore the mailing. B-responses require a valid registration number (e.g., from the registration of another household member). If GIS

\footnotetext{
${ }^{15}$ Harrison and List emphasize that the knowledge about being observed can induce a Hawthorne effect on its own. Such an effect would be highly undesirable in empirical research that studies compliance with the law. See Levitt and List (2007) for a general discussion of this issue.

${ }^{16}$ Individuals may register online, by calling GIS' service hotline, or by sending a filled hard-copy registration form that is available at banks, postal offices, etc.
} 
cannot match the stated number with their data, the response is classified as category D. Finally, C-types may respond in category $\mathrm{C}$ or not at all. ${ }^{17}$

Note that one can unambiguously link A- and B-responses to particular types. Only those who do not comply with the payment duty (A-types) can register for license fees (A-response) and only law-abiding individuals (B-types) can send an update of contract details (B-response). The primary focus of GIS is to maximize A-responses, i.e., revenues. B-responses are their secondary target. Updates about existing registrations allow GIS to improve the targeting of their enforcement measures (mailings and field inspections) on the non-compliant population. In the following, we will analyze both A- and B-responses. This allows us to study whether strategies that are successful in enforcing compliance (a high rate of A-responses) cause any undesirable spillovers on law-abiding individuals (on B-responses). A type-specific response analysis is also interesting from a theoretical point of view. As A- and B-types face different incentives to respond, the comparison of A- and B-responses enables us to infer the causal effects driving the response to our interventions.

\section{Discussion of Treatments}

\subsection{A-Responses}

Consider an A-type who chooses between registering - i.e., paying license fees - and not registering her TV. If she does not register and continues to evade the fee, she will be detected with some probability. In this case, the evader has to pay the fee, supplemental payments and maybe a fine. Rational decision makers trade off these potential costs with the benefits from (not) registering (Becker, 1968). The decision depends on their risk preferences and - with imperfect information on enforcement (Sah, 1991) - the perceived sanction risk.

No-mailing Treatment. Comparing the no-mailing group, T0, with the mailing treatments, T1-T6, the mere fact of receiving a mailing signals that GIS suspects the recipient

\footnotetext{
${ }^{17}$ One could think of several other possibilities: an A-type could assert incorrectly that someone else in the household pays fees. However, based on the registration number, this would be discovered and the response would be coded as unclassified feedback. B-types might make a mistake and register a second time. Such errors would be discovered by GIS, which is obliged to cancel the double registration. C-types could start to pay license fees even if they do not have any broadcasting receivers - a scenario that is highly unlikely. All three types can produce a response of class D.
} 
of violating the law. The A-types in the no-mailing group do not receive this surveillance signal. Hence, we conjecture that mailing recipients perceive a higher sanction risk and are therefore more likely to register than individuals in the no-mailing condition. This effect should be intensified by the mailings, lowering the transaction cost of a registration. ${ }^{18}$

Turning to the mailing treatments, it is important to recall that our six treatments neither changed the 'true' economic incentives for compliance - the actual detection risk and the magnitude of the sanctions were constant across all treatments - nor did they alter the transaction costs for registering. It follows that any behavioral change in response to our mailing treatments must be brought about by changes in the recipients' perceptions.

Legal Threat. The legal threat aims at enforcing compliance through intervening directly with the perceived sanction risk. For the treatment to work, two conditions must hold: first, the threat has to affect risk perceptions and, second, individuals who perceive a higher sanction risk must be more likely to stop breaching the law. If these conditions are met, the legal threat will increase the number of registrations. Regarding the first condition, there should be room for manipulation if individuals have subjective expectations. ${ }^{19}$ While this finds ample empirical support (e.g., Lochner, 2007), there is still no clear-cut evidence to which extent policy changes - e.g., an increase in enforcement efforts - translate into changes of risk perceptions (Nagin, 1998). For instance, mailing recipients might not take the threat to be credible (Graetz et al., 1986). Even if they do, it is an open question whether the treatment shocks perceptions beyond the level that is induced by the mere fact of receiving any mailing.

Given that our manipulation successfully increases risk perceptions, it is still not certain that the threat will trigger more registrations. This point is made by the motivation crowding literature that considers the possibility of increased external incentives - in the form of stricter enforcement - crowding out the intrinsic motives for compliance with the law (Frey, 1997; Benabou and Tirole, 2006). Evidence in support of this case is provided by Gneezy and Rustichini (2000), who showed that introducing a fine reinforced

\footnotetext{
${ }^{18}$ Recall that individuals in the no-mailing group can make an unsolicited registration by picking up, filling and sending in a hard-copy registration form, or by registering online or by phone. In the context of charitable giving, Huck and Rasul (2009) find strong transaction cost effects from mailing letters. One might further argue that mailings simply remind 'unintentional evaders' of their legal duty. This effects is very unlikely to happen, as GIS runs intensive media campaigns that clarify the obligations emerging from the License Fee Act. During the time of the experiment, for instance, GIS placed on average three spots per day in countrywide broadcasted channels.

${ }^{19}$ Manski (2004) offers a review of the subjective expectations literature. For recent contributions on the role of subjective expectations for law enforcement, see Lochner (2007) and Hjalmarsson (2009).
} 
the sanctioned behavior. Slemrod et al. (2001) observed an equally counterintuitive effect. Threatening taxpayers with an increased audit probability resulted in a decline of reported income among high-income groups. ${ }^{20}$

Social Information. There are two alternative channels over which the social information treatment can affect the decision to register. The first builds upon standard deterrence incentives and derives from the 'broken windows theory' (Wilson and Kelling, 1982). According to this approach, signs of non-compliance ('broken windows') may signal lax enforcement and thereby trigger further deviations from the law. The information about a $94 \%$ compliance rate should thus have a positive effect on registrations from individuals who initially expect lower levels of compliance. The opposite holds for those who initially consider compliance to be higher than communicated.

Social norms and conformity motives are the second channel for the information treatment to influence behavior (Elster, 1989; Bernheim, 1994). This is pointed out by legal scholars, who argue that compliance is enforced not only by formal, but also by informal social sanctions (see the references in footnote 1). As norm enforcement is considered to be stronger the more people adhere to a social norm, individuals might condition their compliance on others' norm-adherence (similar to conditional cooperation; see, e.g., Fischbacher and Gächter, 2009). The case for conditional compliance with the law is made by Traxler and Winter (2009), who find that half of the participants in a national survey in Austria are willing to impose sanctions on license fee evaders. They further show that the inclination to sanction declines with the belief about the pervasiveness of noncompliance. If this pattern is correctly anticipated, we arrive at the same prediction as above: among those who initially expect low compliance rates, the social information will signal that social (rather than legal) sanctions are stronger than expected. In turn, this should increase registrations. ${ }^{21}$

Moral Appeal. The moral appeal treatment stresses that evading license fees harms honest households, which violates not only the legal, but also a fairness norm. Psychology

\footnotetext{
${ }^{20}$ These findings relate to a growing number of studies that demonstrate detrimental effects of economic incentives (Fehr and List, 2004; Falk and Kosfeld, 2006; Ariely et al., 2009).

${ }^{21}$ Similar caveats apply to this hypothesis as for the legal threat. In particular, it is not clear whether the nationwide compliance rate (rather than a local rate) shapes perceptions about legal or social sanctions. Moreover, the importance of social interaction in evasion behavior is still elusive, as shown by Fortin et al. (2007), who do not find any social interaction in a lab experiment, and by Galbiati and Zanella (2008), who find a large social multiplier in evasion behavior.
} 
research has illustrated the importance of personal norms and moral concepts - as well as their salience - as driving forces of behavior (Cialdini, 1998). Individuals' judgements seem to be guided by moral shortcuts that are sensitive to framing effects (Sunstein, 2004). Provided that our framing makes a relevant moral concept more salient, one might expect the moral appeal to have a positive impact on registrations.

This prediction is at odds with several studies in the domain of tax enforcement that hardly find any evidence on the effectiveness of moral suasion (Blumenthal et al., 2001; Wenzel and Taylor, 2004). From an economic perspective this is not surprising: the appeal has no informational content and preferences, even when they reflect social motives, are considered to be stable. Quite on the contrary, the treatment might even backfire as the moral appeal could "be read as a sign that the enforcement system cannot cope and must resort to rhetoric instead" (Bardach, 1989, p. 62).

\subsection{B-Responses}

Remember that B-types are equally obliged to respond to the mailings as A-types. However, GIS never imposes sanctions on complying individuals when they do not respond. Hence, there are zero costs for not responding. At the same time, responding entails only minor transaction costs since the return mailing is postpaid. From an economic perspective, it is therefore difficult to assess the treatments' impact - in particular, the effect of the moral appeal and the social information - on B-types' response behavior. Of course, B-types might not be aware that they face no sanction risk or they simply want to avoid an interaction with a field inspector - an event they may find embarrassing even if there are no material consequences at stake. Moreover, signalling models in the fashion of Benabou and Tirole (2006) suggest that B-types have a desire to signal that they are 'good guys' who comply with their legal duty. All these motives might interact with the legal threat.

According to signaling models, the legal threat could have a detrimental effect on Bresponses, if the treatment reduces the value of the 'good type'-signal for B-types. If the expected embarrassment from a field inspection drives the response, or if B-types expect economic sanctions, the threat should increase the frequency of B-responses, as long as the treatment increases the perceived chance of an inspection. The impact of the threat 
should be smaller, however, the lower the expected costs from an inspection are. This has a straightforward implication for the comparison of response between A- and B-types. Given that the threat does increase the perceived inspection risk of both types, B-types should be less sensitive to the threat than A-types as long as the former expect lower sanctions than the latter.

\section{Results of the Experiment}

We now turn to the results from the field experiment. Sections 5.1 and 5.2 provide a non-parametric analysis of the treatment effects. Section 5.3 complements the analysis by estimation results. Section 5.4 offers evidence on interaction effects of the information as well as the threat treatment with municipality characteristics. A detailed discussion of our findings is deferred to section 7 .

\subsection{Overall effect of sending mailings}

Table 3 compares the frequency of registrations (A-responses) in treatments T1-T6 to the unsolicited registrations in the control group (T0) in intervals of 25 days. ${ }^{22}$ Within 25 days after sending the first mailings, only 8 out of the 2,586 individuals (0.31\%) registered for license fees in the no-mailing group. In contrast, 2,794 out of 47,912 mailings (5.83\%) resulted in a registration within the first 25 days after sending the respective mailing. The difference is highly significant $(p=0.000$, according to a two-sided test on the equality of proportions). In the second 25 days, the registration rate was $0.50 \%$ in the control group and $1.83 \%$ in the mailing treatments $(p=0.000)$. Beyond 50 days, we do not observe any differences in registration rates. Hence, the impact of the mailings on registrations is limited to the first 50 days.

After 50 days, $0.81 \%$ of the individuals in the no-mailing condition were registered. In the mailing treatments, the cumulated registration rate was $7.67 \%$ - nearly 10 times higher. Assuming that newly registered households pay license fees for at least one year, the expected revenue per mailing (net of the marginal cost for printing, postage, etc.)

\footnotetext{
${ }^{22} \mathrm{~A}$ similar picture emerges if biweekly or weekly intervals are considered.
} 
Table 3: Registrations per 25-days intervals

\begin{tabular}{l|rl|rl}
\hline \hline Registrations & \multicolumn{2}{|c|}{ T0 } & \multicolumn{2}{|c}{ T1-T6 } \\
\hline days 1-25 & 8 & $0.31 \%$ & 2,794 & $5.83 \%$ \\
days 26-50 & 13 & $0.50 \%$ & 877 & $1.83 \%$ \\
days 51-75 & 9 & $0.35 \%$ & 166 & $0.35 \%$ \\
days 76-100 & 5 & $0.19 \%$ & 95 & $0.20 \%$ \\
\hline Sample & 2,586 & & 47,912 & \\
\hline \hline
\end{tabular}

Notes: Percentages are registration rates relative to the total number of observations in T0 and T1-T6, respectively. For intervals marked with *, the difference in registration rates is significant at a $1 \% 0^{-}$-level.

amounts to $€ 15 .^{23}$ We conclude that the mailing campaign is highly effective in raising revenues. As discussed above, the huge effect of the mailings can be due to reduced transaction costs, the mailings' impact on the perceived sanction risk, or to a combination of both effects. In section 6, we will present further evidence that allows to assess the relevance of these possible causes.

\subsection{Effects of the mailing treatments}

Table 4 summarizes the results for the mailing treatments T1-T6. On average, $14.41 \%$ of the mailings could not be delivered because of erroneous addresses resulting from typos in individual and street names in the GIS data base. Due to the random assignment, however, the share of non-delivered mailings does not statistically differ between treatments ( $\chi^{2}$-test: $\left.p=.793\right)$. In the following, we report responses relative to mailings delivered rather than mailings sent. Motivated by the results from above, we focus on the response within 50 days. All our results are robust to extending this observation period.

Consider first A-responses. Recall that only evaders (A-types) can register. The share of registrations thus measures the treatments' success in enforcing compliance. Table 4 shows that, on average, $8.95 \%$ of recipients responded with a registration of their TV or radio. ${ }^{24}$ A comparison of the registration rates reveals a significant positive effect of the

\footnotetext{
${ }^{23}$ According to GIS, one year is a very conservative assumption on the average registration spell. The calculation further accounts for the fact that, in our sample, $95 \%$ registered TV plus radio and $5 \%$ registered only a radio, resulting in a reduced fee (see footnote 8 ).

${ }^{24}$ As the precise distribution of A-, B- and C-types in our sample is not identified, one cannot judge whether the $8.95 \%$ corresponds to a particularly low or high type-specific response rate. For a closer discussion, see Appendix IV.
} 
Table 4: Mailing Response within 50 Days

\begin{tabular}{|c|c|c|c|c|c|c|c|c|c|c|c|c|c|c|}
\hline & \multicolumn{2}{|c|}{$\begin{array}{c}\text { T1 } \\
\text { Control }\end{array}$} & \multicolumn{2}{|c|}{$\begin{array}{c}\text { T2 } \\
\text { Threat }\end{array}$} & \multicolumn{2}{|c|}{$\begin{array}{l}\text { T3 } \\
\text { Info }\end{array}$} & \multicolumn{2}{|c|}{$\begin{array}{c}\text { T4 } \\
\text { Info\&Threat }\end{array}$} & \multicolumn{2}{|c|}{$\begin{array}{c}\text { T5 } \\
\text { Moral }\end{array}$} & \multicolumn{2}{|c|}{$\begin{array}{c}\text { T6 } \\
\text { Moral\&Threat }\end{array}$} & \multicolumn{2}{|c|}{ Total } \\
\hline Mailings sent & 7,984 & & 7,821 & & 7,998 & & 8,101 & & 8,084 & & 7,924 & & 47,912 & \\
\hline Non-Deliverable & 1,126 & $14.10 \%$ & 1,127 & $14.41 \%$ & 1,173 & $14.67 \%$ & 1,141 & $14.08 \%$ & 1,164 & $14.40 \%$ & 1,174 & $14.82 \%$ & 6,905 & $14.41 \%$ \\
\hline Mailings delivered & 6,858 & & 6,694 & & 6,825 & & 6,960 & & 6,920 & & 6,750 & & 41,007 & \\
\hline A. Registrations & 591 & $8.62 \%$ & 647 & $9.67 \%$ & 562 & $8.23 \%$ & 675 & $9.70 \%$ & 567 & $8.19 \%$ & 629 & $9.32 \%$ & 3,671 & $8.95 \%$ \\
\hline B. Updates & 1,998 & $29.13 \%$ & 1,991 & $29.74 \%$ & 1,875 & $27.47 \%$ & 1,938 & $27.84 \%$ & 1,790 & $25.87 \%$ & 1,908 & $28.27 \%$ & 11,500 & $28.04 \%$ \\
\hline C. No Equipment & 172 & $2.51 \%$ & 203 & $3.03 \%$ & 162 & $2.37 \%$ & 179 & $2.57 \%$ & 163 & $2.36 \%$ & 179 & $2.65 \%$ & 1,058 & $2.58 \%$ \\
\hline D. Unclassified & 194 & $2.83 \%$ & 172 & $2.57 \%$ & 179 & $2.62 \%$ & 185 & $2.66 \%$ & 166 & $2.40 \%$ & 174 & $2.58 \%$ & 1,070 & $2.61 \%$ \\
\hline Overall Response & 2,955 & $43.09 \%$ & 3,013 & $45.01 \%$ & 2,778 & $40.70 \%$ & 2,977 & $42.77 \%$ & 2,686 & $38.82 \%$ & 2,890 & $42.81 \%$ & 17,299 & $42.19 \%$ \\
\hline
\end{tabular}

Notes: Percentage of non-delivered mailings relative to the total number of mailings. Percentages for (A-D and overall) response rates are relative to the number of delivered mailings.

legal threat between T1 and T2 $(p=0.034)$, T3 and T4 $(p=0.003)$, and between T5 and T6 $(p=0.020) .{ }^{25}$ In contrast, neither the social information nor the moral appeal have any significant effects (T1 vs. T3: $p=0.320$, T1 vs.T5: $p=0.369$ ). This finding does not change when the two treatments are interacted with the threat (T2 vs. T4: $p=0.948$; T2 vs. T6: $p=0.493)$.

Second, we turn to B-responses. Table 4 indicates that $28.04 \%$ updated their information on a valid registration. The legal threat shows no effect between the treatments T1 and T2 $(p=0.437)$, nor between T3 and T4 $(p=0.625)$. It is significant only between T5 and T6 $(p=0.002)$, when it interacts with the moral appeal treatment. However, the moral framing per se has a significantly negative impact on update responses (T1 vs. T5: $p=0.000)$. In treatment $\mathrm{T} 6$, the threat only partially counterbalances this negative effect, so that the response rate is still below the one in treatment T2 (T2 vs. T6: $p=0.059$ ). The social information treatment also triggers a significant decline in B-responses (T1 vs. T3: $p=0.031 ; \mathrm{T} 2$ vs. T4: $p=0.014)$.

Finally, for category C responses - individuals who declare not to have any broadcasting receiver - the legal threat has a slightly positive impact that is significant at a 10\%-margin between treatment T1 and T2 $(p=0.063)$. Unlike for A- and B-responses, this effect cannot be attributed to a single type: it could be driven either by A-types who pretend not to hold a broadcasting receiver or by honestly-responding C-types. Concerning category D (unclassified response), there are no significant treatment effects.

\footnotetext{
${ }^{25}$ The treatments also affect how quickly mailing recipients respond with a registration. The time pattern of A-responses is discussed in Appendix III.
} 


\subsection{Regression analysis of treatments}

A-Responses. We complement the analysis by estimating regressions on A-responses. As dependent variable we use a dummy $P_{i}^{A}$ that indicates whether individual $i$ registered (A-response) within 50 days. ${ }^{26}$ We consider the model

$$
P_{i}^{A}=\alpha+\beta \text { Mailing }_{i}+\gamma_{1} \text { Threat }_{i}+\gamma_{2} \text { Moral }_{i}+\gamma_{3} \text { Info }_{i}+\varepsilon_{i} .
$$

The variable Mailing $_{i}$ captures the basic effect of receiving a mailing, taking registrations in the no-mailing condition as benchmark. Threat ${ }_{i}$, Info $_{i}$ and Moral $_{i}$ are treatment dummies equal to one if individual $i$ received a mailing that included the legal threat (T2, T4, and T6), social information (T3 and T4) or a moral appeal (T5 and T6), respectively. The $\gamma$-coefficients thus measure the treatments' impact on registrations, relative to the baseline mailing T1. To account for potential interactions between the treatments, we step-by-step include Threat $\times$ Moral $_{i}$ and Threat $\times \operatorname{Info}_{i}$ in equation (1). All equations are estimated using the linear probability model. ${ }^{27}$ The results are reported in table 5.

The regressions confirm our findings from above. Receiving a mailing has a significant and strongly positive effect on registrations. Among the different mailing treatments, the threat significantly increases individuals' propensity to register by one percentage point. Neither the moral appeal nor the social information have a significant effect. The outcome from column (I) remains unchanged when we account for treatment interactions: none of the interaction terms in columns (II) to (IV) is statistically significant. ${ }^{28}$ While the first set of estimations is based on the full sample of 50,498 observations, we drop the no-mailing sample and exclude all observations with non-deliverable mailings in columns

\footnotetext{
${ }^{26}$ As discussed in Appendix IV, this variable - which is insensitive to responses from B- and C-types - is determined by the share of A-types in the sample and their response behavior. The accurate frequency of A-types is not identified. Moreover, one cannot simply make use of the bounds on the type distribution that are implied by the frequency of B-responses, since these responses are also sensitive to the treatments. Our estimations assume that each mailing recipient could produce an A-response. This yields consistent estimates of the treatment effects on the observed registration frequency for our sample. However, as there is a non-negligible share of B-types, we will underestimate the type specific treatment effects (see Appendix IV).

${ }^{27}$ In the following, we estimate equations with many interaction terms as explanatory variables. Computing correct interaction effects in non-linear models becomes tedious and computationally quite intensive (see Ai and Norton, 2003). Therefore, and to ease comparability between estimations, we employ the linear probability model throughout the whole paper. The results from tables 5 and 6 are basically identical to those from probit estimations, which are available from the authors upon request.

${ }^{28}$ Based on the estimations in columns (IV) and (VIII), an F-test indicates that one cannot reject the null that both interaction terms equal zero $(p=0.728$ and $p=0.814$, respectively).
} 
Table 5: Treatment effects on registrations (A-responses)

\begin{tabular}{|c|c|c|c|c|c|c|c|c|}
\hline \multicolumn{9}{|c|}{ Dependent variable: Registrations (within 50 days) } \\
\hline & (I) & (II) & (III) & (IV) & $(\mathrm{V})$ & $(\mathrm{VI})$ & (VII) & (VIII) \\
\hline Mailing & $\begin{array}{l}0.065^{\star \star \star} \\
(0.003)\end{array}$ & $\begin{array}{l}0.065^{\star \star \star} \\
(0.003)\end{array}$ & $\begin{array}{l}0.066^{\star \star \star} \\
(0.003)\end{array}$ & $\begin{array}{c}0.066^{\star \star \star} \\
(0.003)\end{array}$ & & & & \\
\hline Threat & $\begin{array}{l}0.010^{\star \star \star} \\
(0.002)\end{array}$ & $\begin{array}{l}0.011^{\star \star \star} \\
(0.003)\end{array}$ & $\begin{array}{l}0.009^{\star \star \star} \\
(0.003)\end{array}$ & $\begin{array}{l}0.009^{\star \star} \\
(0.004)\end{array}$ & $\begin{array}{l}0.012^{\star \star \star} \\
(0.003)\end{array}$ & $\begin{array}{l}0.013^{\star \star \star} \\
(0.003)\end{array}$ & $\begin{array}{l}0.011^{\star \star \star} \\
(0.003)\end{array}$ & $\begin{array}{c}0.010^{\star \star} \\
(0.005)\end{array}$ \\
\hline Moral & $\begin{array}{c}-0.004 \\
(0.003)\end{array}$ & $\begin{array}{c}-0.003 \\
(0.004)\end{array}$ & $\begin{array}{c}-0.004 \\
(0.003)\end{array}$ & $\begin{array}{c}-0.004 \\
(0.004)\end{array}$ & $\begin{array}{c}-0.004 \\
(0.003)\end{array}$ & $\begin{array}{c}-0.003 \\
(0.004)\end{array}$ & $\begin{array}{c}-0.004 \\
(0.003)\end{array}$ & $\begin{array}{c}-0.004 \\
(0.005)\end{array}$ \\
\hline Info & $\begin{array}{c}-0.002 \\
(0.003)\end{array}$ & $\begin{array}{c}-0.002 \\
(0.003)\end{array}$ & $\begin{array}{c}-0.004 \\
(0.004)\end{array}$ & $\begin{array}{c}-0.004 \\
(0.004)\end{array}$ & $\begin{array}{c}-0.002 \\
(0.003)\end{array}$ & $\begin{array}{c}-0.002 \\
(0.003)\end{array}$ & $\begin{array}{c}-0.004 \\
(0.004)\end{array}$ & $\begin{array}{c}-0.004 \\
(0.005)\end{array}$ \\
\hline Threat $\times$ Moral & & $\begin{array}{c}-0.002 \\
(0.005)\end{array}$ & & $\begin{array}{c}0.001 \\
(0.006)\end{array}$ & & $\begin{array}{c}-0.001 \\
(0.006)\end{array}$ & & $\begin{array}{c}0.001 \\
(0.007)\end{array}$ \\
\hline Threat $\times$ Info & & & $\begin{array}{c}0.004 \\
(0.005)\end{array}$ & $\begin{array}{c}0.004 \\
(0.006)\end{array}$ & & & $\begin{array}{c}0.004 \\
(0.006)\end{array}$ & $\begin{array}{c}0.004 \\
(0.007)\end{array}$ \\
\hline Constant & $\begin{array}{l}0.008^{\star \star \star} \\
(0.002)\end{array}$ & $\begin{array}{l}0.008^{\star \star \star} \\
(0.002)\end{array}$ & $\begin{array}{l}0.008^{\star \star \star} \\
(0.002)\end{array}$ & $\begin{array}{l}0.008^{\star \star \star} \\
(0.002)\end{array}$ & $\begin{array}{l}0.085^{\star \star \star} \\
(0.003)\end{array}$ & $\begin{array}{l}0.085^{\star \star \star} \\
(0.003)\end{array}$ & $\begin{array}{l}0.086^{\star \star \star} \\
(0.003)\end{array}$ & $\begin{array}{l}0.086^{\star \star \star} \\
(0.003)\end{array}$ \\
\hline Observations & 50,498 & 50,498 & 50,498 & 50,498 & 41,007 & 41,007 & 41,007 & 41,007 \\
\hline
\end{tabular}

Notes: All specifications are estimated with a linear probability model. (I)-(IV) are based on the full sample, (V)-(VIII) drops the no-mailing sample and observations where a mailing was not delivered. Robust standard errors are in parentheses. ${ }^{\star \star \star}$ and ${ }^{\star \star}$ indicate significance at a $1 \%$ and $5 \%$-level, respectively.

(V)-(VIII). ${ }^{29}$ The second set of estimations reveals that the point estimates of the treatment effects hardly change. As a further robustness check we include additional control variables, like recipients' gender and several municipality characteristics in the estimations (see table A.1 in Appendix II). Adding these variables leaves the estimates basically unaffected, demonstrating that the controls are orthogonal to our treatments due to the successful randomization.

The results provided above corroborate the economic model of crime. Threatening evaders with inspections clearly works as an enforcement strategy, whereas the moral appeal and the social information fail. The legal threat increases the registration rate by slightly more than one percentage point as compared to an estimated 8.5 percentage points for the baseline mailing. This suggests that the threat successfully altered individuals' risk perceptions. (We will discuss additional evidence that supports this interpretation below.) The registration rates in the legal threat treatments are about $15 \%$ above the rates in the mailing treatments without the threat paragraph. Under conservative assumptions (see footnote 23), our change in the wording of the cover letter thus produced an increase in

\footnotetext{
${ }^{29}$ Information on erroneous addresses, i.e., non-delivered mailings, is not available for the no-mailing sample.
} 
expected revenues per delivered mailing of $€ 2.50$. For the 100,000 mailings delivered by GIS per year, this would correspond to an additional revenue of $€ 250,000$.

In contrast to the legal threat, the strategies based on moral appeals and the provision of social information (further discussed below) fail to increase compliance. The ineffectiveness of the moral appeal, however, does not necessarily indicate that moral standards are irrelevant for compliance with the law. As our mailings were targeted to a specific sample of individuals who deviate from the law, it is likely that they do not share the activated moral value (Meares et al., 2004). This interpretation is supported by evidence of Pruckner and Sausgruber (2008), who report that people respond to a moral appeal only if they have internalized a norm against cheating.

B-Responses. Next, we consider the treatments impact on update responses. We regress the dummy variable $P_{i}^{B}$ that indicates whether individual $i$ updated her contract detail, on our treatment variables. ${ }^{30}$ As we cannot measure contract updates among the no-mailing group, we focus on the mailing sample and exclude data on non-delivered mailings.

While column (I) in table 6 indicates a positive effect of the legal threat, columns (II) and (IV) show that the effect is not robust when we account for the interaction between the threat and the moral appeal. The interaction term is significant in specification (II), but not in (IV). ${ }^{31}$ For all specifications presented in table 6 , the main treatment effects of the moral appeal and the social information are significantly negative. Like above, adding additional control variables does not affect the estimation results.

The estimations, in particular the full model in specification (IV), show no robust effect of the legal threat. This suggests that B-types are not driven by the desire to avoid an interaction with a field inspector. Given that law-abiding individuals are aware that they face no real sanction threat, the evidence is consistent with the deterrence hypothesis and, at the same time, with the significantly positive response of A-types to the threat: A-types fear sanctions and are thus sensitive to legal threats. B-types do not expect any fines and are thus insensitive. Section 6 provides further evidence on A- and B-types' perceptions, which supports this interpretation.

\footnotetext{
${ }^{30}$ Regarding type identification, similar caveats apply as above (see footnote 26 and Appendix IV).

${ }^{31} \mathrm{An}$ F-test does not reject the joint hypothesis of both interaction terms being zero $(p=0.121$ for specification (IV). However, the F-test clearly rejects the null of the Threat and Threat $\times$ Moral being both zero $(p=0.005$ for $(\mathrm{IV}))$.
} 
Table 6: Treatment effects on contract updates (B-responses)

\begin{tabular}{|c|c|c|c|c|}
\hline \multicolumn{5}{|c|}{ Dependent variable: Update responses (within 50 days) } \\
\hline & $(\mathrm{I})$ & (II) & (III) & $(\mathrm{IV})$ \\
\hline \multirow[t]{2}{*}{ Threat } & $0.011^{\star \star}$ & 0.005 & $0.015^{\star \star \star}$ & 0.006 \\
\hline & $(0.004)$ & $(0.005)$ & $(0.005)$ & $(0.008)$ \\
\hline \multirow[t]{2}{*}{ Moral } & $-0.024^{\star \star \star}$ & $-0.033^{\star \star \star}$ & $-0.024^{\star \star \star}$ & $-0.033^{\star \star \lambda}$ \\
\hline & $(0.005)$ & $(0.007)$ & $(0.005)$ & $(0.008)$ \\
\hline \multirow[t]{2}{*}{ Info } & $-0.018^{\star \star \star}$ & $-0.018^{\star \star \star}$ & $-0.012^{\star}$ & $-0.017^{\star \star}$ \\
\hline & $(0.005)$ & $(0.005)$ & $(0.007)$ & $(0.008)$ \\
\hline \multirow[t]{2}{*}{ Threat $\times$ Moral } & & $0.019^{\star \star}$ & & 0.018 \\
\hline & & $(0.009)$ & & $(0.011)$ \\
\hline \multirow[t]{2}{*}{ Threat $\times$ Info } & & & -0.011 & -0.002 \\
\hline & & & $(0.009)$ & $(0.011)$ \\
\hline \multirow[t]{2}{*}{ Constant } & $0.289^{\star \star \star}$ & $0.287^{\star \star \star}$ & $0.292^{\star \star \star}$ & $0.291^{\star}$ \\
\hline & $(0.004)$ & $(0.005)$ & $(0.005)$ & $(0.005)$ \\
\hline Observations & 41,007 & 41,007 & 41,007 & 41,007 \\
\hline
\end{tabular}

Notes: All specifications are estimated with a linear probability model. Robust standard errors are in parentheses. ${ }^{\star \star \star},{ }^{\star \star}$, * indicate significance at a $1 \%, 5 \%, 10 \%$-level, respectively.

It is not straightforward to explain the negative effect observed for the moral appeal and the social information treatment. Both treatments have in common that they point to non-compliance. The moral framing, for instance, explicitly reminds B-types of being cheated ('...harm all honest households'). Stressing the fact that some people cheat them might undermine the law-abiding individuals' propensity to respond to the mailing. The threat may offset this effect, as it documents the authority's efforts to impose sanctions on those who do not comply with their legal duties, thus resulting in the positive interaction found in specification (II).

\subsection{Interaction Effects with Municipality Characteristics}

\subsubsection{Social Information}

The fact that the social information treatment did not increase A-responses on aggregate is not conclusive for a final evaluation of this treatment. As discussed in section 4, providing social information should increase registrations only among those who initially expect compliance to be lower than communicated. GIS did neither allow us to experimentally vary the communicated compliance level (similar to Frey and Meier, 2004) nor to elicit 


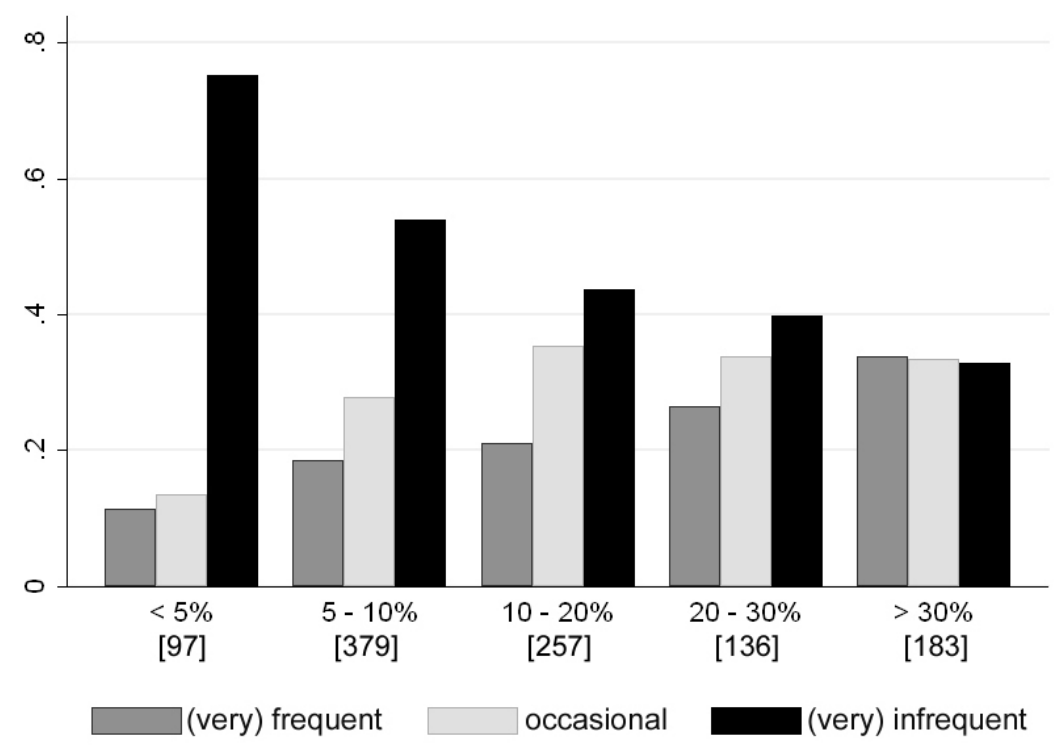

Figure 1: Beliefs about TV license fee evasion

Notes: The figure plots the response distribution on beliefs about the frequency of license fee evasion in Austria for regions with an estimated local evasion rate of $0-5 \%, 5-10 \%, 10-20 \%, 20-30 \%$ and above $30 \%$. The number of observations in the five categories is displayed in squared brackets.

prior beliefs in our sample. We therefore evaluate the prediction by exploiting a link between individual beliefs and local evasion levels estimated by GIS.

In a national survey conducted in the year 2000, more than 1000 Austrian households were asked to state their belief about the frequency of license fee evasion (see Traxler and Winter, 2009). Figure 1 plots the distribution of the response (measured on a five-point Likert scale ranging from 'very frequent' to 'very infrequent') against GIS' estimate of the local evasion rate (in the categories $0-5 \%, 5-10 \%, 10-20 \%, 20-30 \%$ and above 30\%) in the respondent's home district at the time of the survey. ${ }^{32}$ The figure reveals a strong correlation of beliefs with the local evasion levels. In regions with an evasion rate below $5 \%$, more than $75 \%$ believe that dodging the fee is infrequent or very infrequent. In districts with evasion levels above $30 \%$, this number drops to $33 \%$. Vice versa, the share of respondents who believe that evasion is frequent or very frequent rises from $11 \%$ in low evasion regions to $34 \%$ in districts with high levels of non-compliance. Estimating ordered probit models that control for individual characteristics confirms this correlation. ${ }^{33}$

\footnotetext{
${ }^{32}$ The estimate for local evasion corresponds to one minus the share of households who are registered for license fees relative to the total number of households living in a jurisdiction (see table 2).

${ }^{33}$ The estimation results are available from the authors upon request.
} 
Provided that beliefs and local evasion levels are similarly correlated for the individuals in our sample, we expect a positive effect of the social information in municipalities with a high evasion rate. This is tested by estimating an equation that interacts our treatment variables with the local evasion level,

$$
\begin{aligned}
P_{i}^{A}= & \alpha+\beta_{1} \text { Threat }_{i}+\beta_{2} \text { Moral }_{i}+\beta_{3} \text { Info }_{i}+\gamma_{0} \text { Evasion }_{i}^{\mathrm{Q} 1} \\
& +\gamma_{1} \text { Threat }_{i} \times \text { Evasion }_{i}^{\mathrm{Q} 1}+\gamma_{2} \text { Moral }_{i} \times \text { Evasion }_{i}^{\mathrm{Q} 1}+\gamma_{3} \text { Info }_{i} \times \text { Evasion }_{i}^{\mathrm{Q} 1} \\
& +X_{i} \delta+\varepsilon_{i},
\end{aligned}
$$

where Evasion $_{i}^{\mathrm{Q} 1}$ is a dummy indicating whether recipient $i$ lives in a municipality that ranges in the top quartile of the local evasion rates. The vector of control variables $\mathrm{X}_{i}$ includes the recipient's gender and several municipality characteristics (see Table A.1 in the Appendix). $\beta_{1}, \beta_{2}$ and $\beta_{3}$ measure the main treatment effects. Any additional effects in high-evasion municipalities are taken up by $\gamma_{1}, \gamma_{2}$ and $\gamma_{3}$; the non-interacted difference in registrations is captured by $\gamma_{0}$. According to our hypothesis, $\gamma_{3}$ as well as $\beta_{3}+\gamma_{3}$, the overall effect of the social information treatment in high evasion municipalities should be positive.

Column (I) in table 7 displays the results from estimating equation (2). In column (II), we introduce a full set of municipality dummies. In both specifications, $\gamma_{3}$ is positive and significant at a $10 \%$ level. In specifications (III) and (IV), where we replace Evasion ${ }_{i}^{\mathrm{Q} 1}$ with Evasion $_{i}^{\mathrm{T} 1}$, a dummy for the top tercile regarding the local evasion rates, we obtain virtually identical results. The estimations document a significantly different effect of the social information treatment in municipalities with widespread non-compliance compared to municipalities with low evasion rates. In the former, providing information has a positive, in the latter a weakly negative effect. However, the treatments' overall impact in high-evader municipalities is not significantly different from the baseline - an F-test does not reject the null hypothesis $\beta_{3}+\gamma_{3}=0(p=0.226$ and $p=0.212$ for specification (I) and (II), respectively). Moreover, we do not observe any significant interaction effect once we estimate a model with linear treatment interactions with the evasion rate Evasion . Hence, the observed effect is not very robust. Finally, it is worth noting that the coefficient from the moral appeal is significantly negative in specification (I) and (III). The moral 
Table 7: Treatment effects on registrations: local evasion

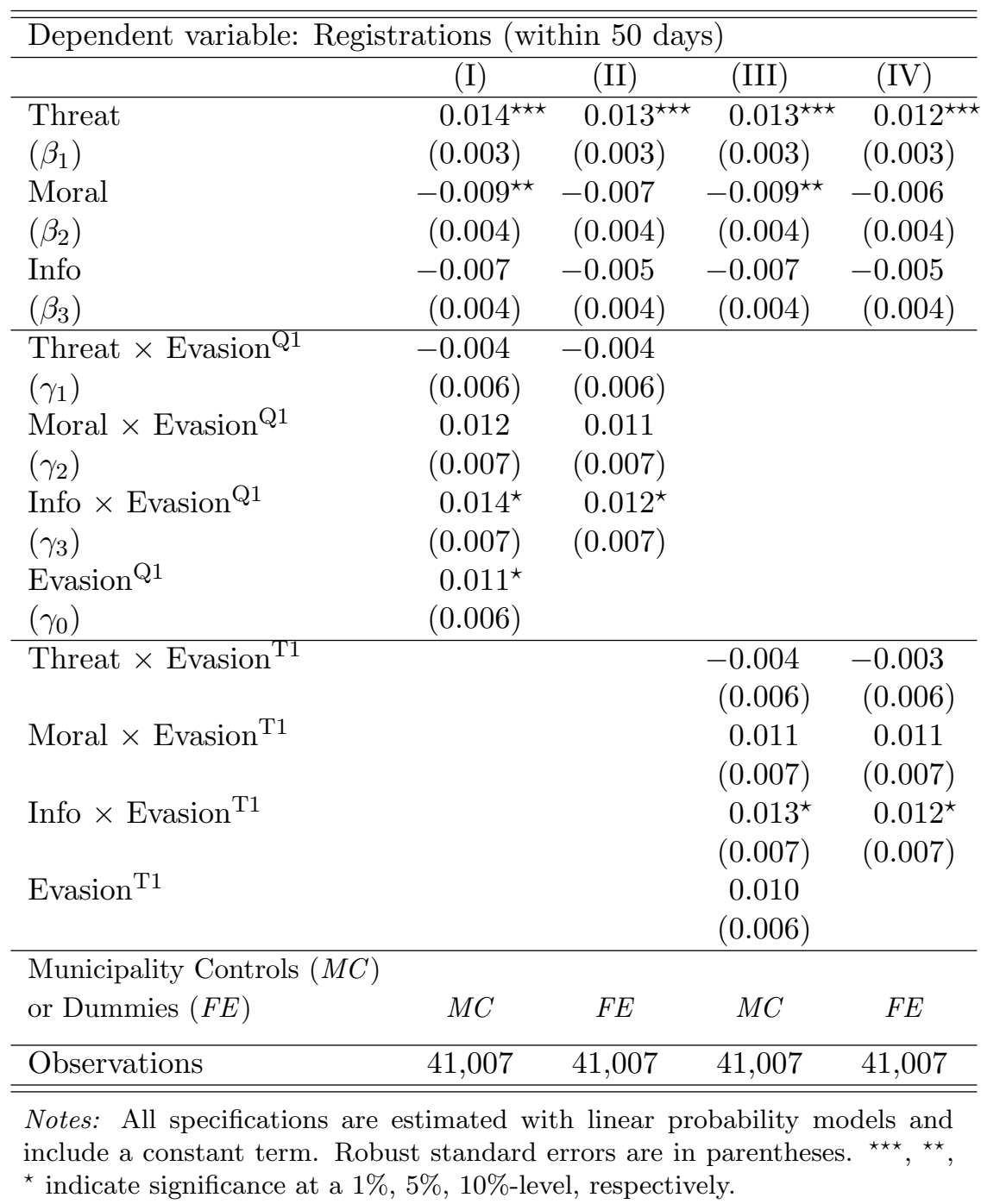

framing tends to exert a significantly negative effect on registrations in a sizable subsample of our study. This effect also appears in the following analysis.

\subsubsection{Legal Threat}

There is substantial heterogeneity across municipalities in our sample. The municipalities' population size, for instance, ranges from a mere 100 to 240,000 individuals for Vienna's largest district. This heterogeneity allows us to explore the role of municipality characteristics in altering the impact of our treatments. We focus on A-responses and estimate interaction models similar to those from above, either including the full set of control 
variables or municipality dummies. The results from these estimations are reported in table 8 .

Table 8: Treatment interactions with municipality characteristics

\begin{tabular}{|c|c|c|c|c|c|c|c|c|}
\hline \multicolumn{9}{|c|}{ Dependent variable: Registrations (within 50 days) } \\
\hline \multirow[t]{2}{*}{ Interactions } & \multicolumn{2}{|c|}{ Population Size } & \multicolumn{2}{|c|}{ High Pop.Density } & \multicolumn{2}{|c|}{ High Income } & \multicolumn{2}{|c|}{ Share of Right Voters } \\
\hline & $(\mathrm{I})$ & (II) & (III) & $(\mathrm{IV})$ & $(\mathrm{V})$ & $(\mathrm{VI})$ & (VII) & (VIII) \\
\hline \multirow[t]{2}{*}{ Threat } & $0.008^{\star \star \star}$ & $0.007^{\star \star}$ & $0.008^{\star \star}$ & $0.006^{\star}$ & $0.009^{\star \star \star}$ & $0.008^{\star \star}$ & $0.042^{\star \star \star}$ & $0.042^{\star \star \star}$ \\
\hline & $(0.003)$ & $(0.003)$ & $(0.003)$ & $(0.003)$ & $(0.003)$ & $(0.003)$ & $(0.013)$ & $(0.013)$ \\
\hline \multirow[t]{2}{*}{ Moral } & $-0.008^{\star \star}$ & -0.005 & $-0.009^{\star \star}$ & -0.006 & -0.006 & -0.002 & 0.002 & 0.000 \\
\hline & $(0.004)$ & $(0.004)$ & $(0.004)$ & $(0.004)$ & $(0.004)$ & $(0.004)$ & $(0.015)$ & $(0.016)$ \\
\hline \multirow[t]{2}{*}{ Info } & -0.002 & -0.000 & -0.002 & 0.000 & -0.002 & -0.001 & 0.005 & 0.005 \\
\hline & $(0.004)$ & $(0.004)$ & $(0.004)$ & $(0.004)$ & $(0.004)$ & $(0.004)$ & $(0.015)$ & $(0.016)$ \\
\hline \multirow[t]{2}{*}{ Threat $\times$ PopSize } & $0.009^{\star \star}$ & $0.010^{\star \star}$ & & & & & & \\
\hline & $(0.004)$ & $(0.004)$ & & & & & & \\
\hline \multirow[t]{2}{*}{ Moral $\times$ PopSize } & 0.006 & 0.005 & & & & & & \\
\hline & $(0.005)$ & $(0.005)$ & & & & & & \\
\hline \multirow[t]{2}{*}{ Info $\times$ PopSize } & -0.000 & -0.001 & & & & & & \\
\hline & $(0.005)$ & $(0.005)$ & & & & & & \\
\hline PopSize & $\begin{array}{c}-0.022^{\star \star \star} \\
(0.008)\end{array}$ & & & & & & & \\
\hline \multirow[t]{2}{*}{ Threat $\times$ PopDens ${ }^{Q 1}$} & & & $0.018^{\star \star \star}$ & $0.020^{\star \star \star}$ & & & & \\
\hline & & & $(0.007)$ & $(0.007)$ & & & & \\
\hline \multirow[t]{2}{*}{ Moral $\times$ PopDens ${ }^{\mathrm{Q} 1}$} & & & $0.015^{\star}$ & 0.011 & & & & \\
\hline & & & $(0.008)$ & $(0.009)$ & & & & \\
\hline \multirow[t]{2}{*}{ Info $\times$ PopDens ${ }^{Q 1}$} & & & -0.001 & -0.004 & & & & \\
\hline & & & $(0.008)$ & $(0.008)$ & & & & \\
\hline PopDens ${ }^{\mathrm{Q} 1}$ & & & $\begin{array}{c}-0.016 \\
(0.010)\end{array}$ & & & & & \\
\hline \multirow[t]{2}{*}{ Threat $\times$ Income $^{Q 1}$} & & & & & 0.010 & $0.012^{\star}$ & & \\
\hline & & & & & $(0.007)$ & $(0.007)$ & & \\
\hline \multirow[t]{2}{*}{ Moral $\times$ Income $\mathrm{I}^{\mathrm{Q}}$} & & & & & 0.002 & -0.002 & & \\
\hline & & & & & $(0.008)$ & $(0.008)$ & & \\
\hline \multirow[t]{2}{*}{ Info $\times$ Income $\mathrm{Q}^{\mathrm{Q} 1}$} & & & & & 0.000 & -0.001 & & \\
\hline & & & & & $(0.008)$ & $(0.009)$ & & \\
\hline Income ${ }^{\mathrm{Q} 1}$ & & & & & $\begin{array}{c}0.000 \\
(0.013)\end{array}$ & & & \\
\hline Threat $\times$ RightVoters & & & & & & & $\begin{array}{c}-0.049^{\star \star \star} \\
(0.019)\end{array}$ & $\begin{array}{c}-0.051^{\star \star \star} \\
(0.019)\end{array}$ \\
\hline Moral $\times$ RightVoters & & & & & & & $\begin{array}{c}-0.011 \\
(0.023)\end{array}$ & $\begin{array}{c}-0.005 \\
(0.023)\end{array}$ \\
\hline \multirow[t]{2}{*}{ Info $\times$ RightVoters } & & & & & & & -0.013 & -0.010 \\
\hline & & & & & & & $(0.023)$ & $(0.023)$ \\
\hline \multirow[t]{2}{*}{ RightVoters } & & & & & & & -0.018 & \\
\hline & & & & & & & $(0.037)$ & \\
\hline Municipality Controls $(M C)$ & $M C$ & $F E$ & $M C$ & $F E$ & $M C$ & $F E$ & $M C$ & $F E$ \\
\hline Observations & 41,007 & 41,007 & 41,007 & 41,007 & 41,007 & 41,007 & 41,007 & 41,007 \\
\hline
\end{tabular}

Notes: All specifications are estimated with a linear probability model and include a constant term. Robust standard errors are in parentheses. ${ }^{\star \star \star},{ }^{\star \star},{ }^{\star}$ indicate significance at a $1 \%, 5 \%, 10 \%$-level, respectively. PopSize measures the population in 1,000 inhabitants; PopDens ${ }^{\mathrm{Q} 1}$ and Income ${ }^{\mathrm{Q} 1}$ are dummies for municipalities in the top quartile of the population density and the gross average incomes, respectively; RightVoters is the share of votes casted to rightist parties (Volkspartei, Freiheitliche and Bündnis Zukunft Österreich) in the 2006 parliamentary elections. 
The first column of the table reveals that the effectiveness of mailings in raising registrations decreases with the population size. Relative to the other mailings, however, the threat is more successful in larger municipalities. The main effect of the threat remains significant in both specifications (I) and (II). This is in line with the results from columns (III) and (IV), which display a stronger effect of the threat in municipalities in the top quartile of population density. The legal threat seems to have a larger effect in urban areas. Like in table 7 , we find a significantly negative effect of the moral appeal in specifications (I) and (III). The latter estimation also indicates a positive interaction with the population density. However, both effects of the moral appeal vanish once we include municipality dummies.

Columns (V) and (VI) further show that the threat is slightly more effective in municipalities with an average income in the top end of the distribution. However, the interaction is only significant at the $10 \%$-level in the FE-specification. Column (VII) and (VIII) report the interaction with the political orientation. The legal threat is most effective in municipalities with many center-left voters and has a weaker effect in more right-leaning municipalities. We considered several additional treatment interactions, for instance with the population inflow into municipalities. This variable should, ceteris paribus, positively correlate with the frequency of evaders who recently moved but did not yet register at the new place (in contrast to those who already evade for a longer time). Estimations did not indicate any significant interaction effects.

Finally, we studied the sensitivity of our results with respect to the municipalities' mailing coverage, i.e., the number of mailings relative to the municipality population. One might suspect that communication between recipients of different mailings could undermine the treatment effects. In fact, we estimate a slightly stronger effect of the legal threat if we exclude the top quartile of municipalities regarding mailing coverage (not reported). Running the estimations from table 7 on the restricted sample, one also obtains a stronger effect of the social information. These stronger treatment effects, however, seem to be driven by type composition rather than by treatment spillover effects. To see this point, note that a high mailing coverage indicates that GIS has little information from prior mailing campaigns in these municipalities and thus addresses many B-types. This is well reflected in our data: the rate of B-responses exceeds $44 \%$ in the top quartile 
regarding mailing coverage, as compared to $24 \%$ in the remaining sample. Excluding high-coverage municipalities, we thus obtain stronger treatment effects on A-responses simply because the frequency of B-types is lower (see Appendix IV). In any case, our findings are highly robust when we account for heterogenous mailing coverage.

\section{Perception Survey}

Our experiment establishes controlled field evidence on the causal impact of different interventions on compliance behavior. To understand better the mechanisms behind these results, we conducted an anonymous survey that evaluates the treatments' impact on subjective perceptions. The web-based survey was implemented among a sample of students from the University of Innsbruck. 3,233 participants completed the survey. Details on the procedure are described in Appendix V.

Survey participants were randomly confronted with one of two scenarios. One scenario described an A-type vignette (a person who moved to a new place six months ago and evades the fee since then), the other one a B-type vignette (someone who moved six month ago, paid the fee, but did not inform GIS about the change in address). After participants read the scenario description, the web page randomly linked them to a situation that mimicked one of the treatments from the field experiment. A random subsample formed the control (T0). All others were instructed that the vignette person received a mailing from GIS. Thereafter a cover letter, which corresponds to one of our six mailing treatments (T1-T6), was displayed on the web page. Survey participants were then asked to evaluate the situation of the person. In this way, we elicited the treatments' impact on perceptions regarding, e.g., the risk of a field inspection, the size of fines, and potential social sanctions.

Consider first how the treatments affect the perceived inspection risk. Table 9 shows the outcome of regressing the stated risk perception (ranging from 0 and 100) on the treatments and the scenario type. By far the largest impact on perceptions is induced by the mailing conditions. After being confronted with a mailing, survey participants evaluate the household's inspection risk to be roughly $60 \%$ higher than in the no-mailing group. ${ }^{34}$ This suggests that the huge overall impact of the mailings observed in the

\footnotetext{
${ }^{34}$ The percentage is based on the estimates from specification (I) in table 9, putting the coefficient for the mailing dummy relative to the constant.
} 
Table 9: Survey results: Treatment effects on risk perceptions

\begin{tabular}{|c|c|c|}
\hline \multicolumn{3}{|c|}{$\begin{array}{l}\text { Dependent variable: } \\
\text { Expected inspection risk }\end{array}$} \\
\hline & (I) & (II) \\
\hline Mailing & $\begin{array}{l}22.923^{\star \star \star} \\
(2.179)\end{array}$ & $\begin{array}{l}24.333^{\star \star \star} \\
(2.183)\end{array}$ \\
\hline Mailing $\times$ Threat & $\begin{array}{l}2.921^{\star \star \star} \\
(1.104)\end{array}$ & $\begin{array}{l}3.193^{\star \star \star} \\
(1.107)\end{array}$ \\
\hline Mailing $\times$ Moral & $\begin{array}{l}0.768 \\
(1.332)\end{array}$ & $\begin{array}{c}-0.056 \\
(1.338)\end{array}$ \\
\hline Mailing $\times$ Info & $\begin{array}{c}-0.306 \\
(1.360)\end{array}$ & $\begin{array}{c}-1.064 \\
(1.362)\end{array}$ \\
\hline A-type & $\begin{array}{c}0.673 \\
(1.103)\end{array}$ & $\begin{array}{c}0.862 \\
(1.104)\end{array}$ \\
\hline Constant & $\begin{array}{l}38.388^{\star \star \star} \\
(2.106)\end{array}$ & $\begin{array}{l}56.801^{\star \star \star} \\
(5.354)\end{array}$ \\
\hline Additional control & No & Yes \\
\hline Observations & 3,213 & 3,098 \\
\hline
\end{tabular}

field experiment is also driven by an alert effect. Next to lowering transaction costs, the mailings signal surveillance and thereby increase the risk perception. Among the mailing treatments, only the legal threat shows a significant effect. Compared to the baseline mailing (T1), the threat increases the expected inspection risk by another $5 \%$. Specification (II) includes control variables on the respondents' personal characteristics. This hardly changes the point estimates of the treatment effects. The same holds true when we estimate Tobit instead of OLS regressions.

Turning to the expected size of fines, we do not find any impact of the legal threat nor any mailing effect. The survey reveals, however, that participants expect significantly lower fines for B- than for A-types ( $p=0.003$, according to a Wilcoxon rank-sum test). Equivalently, B-types are also expected to face significantly weaker social sanctions in case of an inspection $(p=0.003)$. These findings are consistent with the fact that GIS does not impose fines on B-types and supports our interpretation of the heterogenous impact of the legal threat on A- and B-types established in the field experiment (see section 5.2): the legal threat is successful in enforcing registrations because it increases the perceived 
inspection risk and because A-types expect significant sanctions. While the threat also induces B-types to perceive a higher chance of facing a field inspector, the inspection is rationally expected to have few consequences. Thus, the threat treatment does not increase B-responses.

\section{Conclusions}

We tested different strategies to enforce compliance with the law in a large-scale natural field experiment. The experiment manipulated the text of personalized mailings that were sent to potential evaders of TV license fees. Treatment effects were evaluated by comparing the response of recipients, in particular whether evaders start to comply with the payment duty. We gathered supplementary data from a survey that studied the treatments' impact on subjective perceptions. These data enabled us to analyze further the mechanism linking different policy manipulations, perceptions, and behavior. The main contributions of our study are twofold. First, we provide strong and conceptually consistent support for the economic model of crime. Second, we show that alternative enforcement strategies are, by and large, unsuccessful and discuss the reasons for the failure.

Regarding the first contribution, we demonstrate that the authority can successfully deter law violations by manipulating individuals' perceived costs of non-compliance. The study contains three pieces of evidence in support of this conclusion. First, comparing those who received a mailing with an untreated control group, we observe a striking impact of the mailings. The fraction of evaders who start to comply with the payment duty is nearly 10 times higher in the mailing condition. The huge effect is equally reflected in the survey, which reveals that mailings alert individuals to the risk of being detected as violators. In combination with a reduction in transaction costs, this alert effect creates the pronounced change in behavior. Second, adding a legal threat to a neutral letter induces a further, considerable increase in compliance. Because the setup of the experiment excludes incapacitation and displacement effects, the result provides clean, experimental evidence on deterrence in the field. The survey data corroborate the economic model of crime, indicating that the deterrent effect of the threat is caused by increasing individuals' expectations about the price of non-compliance. Finally, we take advantage of the fact that 
our sample consists of heterogenous types: evaders who face potentially severe sanctions and others, who are not exposed to economic sanctions. In line with rational behavior, the legal threat produces a strong response only among the former. Taken together, this first set of results lends compelling support to the economic model of crime.

A further property of the legal threat is that it has no negative effect on the behavior of individuals who abide by the law. This observation is of great importance from a policy perspective: in most natural situations, law-abiding and law-violating individuals are exposed to the same enforcement strategies, just like in our experiment. For an effective enforcement policy, it is therefore essential not to cause detrimental spillovers on the compliant population. Regarding non-compliant individuals, our results show an unrestrictedly positive effect of the threat on compliance. The treatment's success is robust for all strata within our sample and insensitive to interactions with additional treatments. Note, however, that our study only measures short-run responses. In the long run, the effectiveness of legal threats presumably relies on the actual enforcement activities. The costs of maintaining the credibility of deterrent threats stimulate the search for alternative enforcement strategies, leading to our second set of results.

Our second contribution consists of testing moral appeals and the provision of social information as instruments of enforcement. Compared to a neutral mailing, both strategies failed to increase aggregate compliance. To evaluate the ineffectiveness of the moral suasion, it is important to note that our mailings were targeted at a sample of individuals who deviate from the law. Thus, it is likely that the activated moral value is not shared by the recipients. Appealing to a conflicting norm might further reduce the willingness to comply with the law. In line with this interpretation, we find a negative effect of the appeal in large subsamples of our study. Hence, moral appeals are no attractive strategy to enforce compliance among those who deliberately violate the law.

While the social information treatment is ineffective on aggregate, the treatments' impact on behavior crucially relies on individuals' prior beliefs about the compliance of others: with non-common priors, the information that $94 \%$ of all Austrians follow the law can affect beliefs - and thus compliance - in either direction. Our empirical assessment of this hypothesis makes use of supplementary evidence that documents a positive correlation between the perceived and the actual local compliance rate. Exploiting this 
correlation, we uncover significantly different treatment effects in municipalities with low and high compliance rates. In the former, where evasion is believed to be common, the social information has a positive, in the latter a weakly negative impact. This conditional compliance effect, however, is not very strong. To test social information policies comprehensively, future research should experimentally vary the provided information. Already our findings demonstrate that 'belief management', i.e., policy interventions that aim at affecting subjective beliefs, may not be easily applicable to change behavior into the desired direction. With non-common priors, one and the same piece of information can convey different messages and cause contrary reactions. To render belief management successful, it is necessary to communicate the 'right' piece of information to the 'right' target group - a precondition that might be very costly to meet in practice.

To sum up, our study provides clear-cut evidence on deterrence. The experiment documents that legal threats unambiguously work as an enforcement strategy. Neither moral appeals nor imparting social information turn out to increase compliance. Overall, the economic model of crime performs remarkably well in explaining our data. Designing successful enforcement policies that rely on behavioral motives beyond the incentives considered in the Beckerian analysis remains a challenging task for future research. 


\section{References}

Ai, C. and Norton, E. C. (2003). Interaction terms in logit and probit models. Economics Letters, 80 (1), 123-129.

Anderson, S. P. and Coate, S. (2005). Market provision of broadcasting: A welfare analysis. Review of Economic Studies, 72 (4), 947-972.

Ariely, D., Bracha, A. and Meier, S. (2009). Doing Good or Doing Well? Image Motivation and Monetary Incentives in Behaving Prosocially. American Economic Review, 99 (1), 544-555.

BARDACH, E. (1989). Moral suasion and taxpayer compliance. Law and Policy, 11 (1), 49-69.

Becker, G. (1968). Crime and punishment: An economic approach. Journal of Political Economy, 76 (2), 169-217.

Benabou, R. and Tirole, J. (2006). Incentives and prosocial behavior. American Economic Review, 95 (5), 1652-1678.

Bernheim, D. B. (1994). A theory of conformity. Journal of Political Economy, 102 (5), $841-877$.

Blumenthal, M., Christian, C. and Slemrod, J. (2001). Do normative appeals affect tax compliance? evidence from a controlled experiment in minnesota. National Tax Journal, 54 (1), 125-138.

Cialdini, R. (1998). Influence: The Psychology of Persuasion (Revised Version). New York: Collins.

Corman, H. and Mocan, N. (2000). A time-series analysis of crime, deterrence, and drug abuse in new york city. American Economic Review, 90 (3), 584-604.

- and - (2005). Carrots, sticks, and broken windows. Journal of Law \& Economics, 48 (1), 235-66.

Dills, A. K., Miron, J. A. and Summers, G. (2009). What do economists know about crime? In S. Edwards, R. D. Tella and E. Schargrodsky (eds.), Crime, Institutions, and Policies, Chicago: University of Chicago Press, forthcoming.

Ditella, R. and Schargrodsky, E. (2004). Do police reduce crime? estimates using the allocation of police forces after a terrorist attack. American Economic Review, 94 (1), 115-133.

Drago, F., Galbiati, R. and Vertova, P. (2009). The deterrent effects of prison: Evidence from a natural experiment. Journal of Political Economy, 117 (2), 257-280.

Ellickson, R. C. (1998). Law and economics discovers social norms. The Journal of Legal Studies, 27 (2), 537-552.

Elster, J. (1989). The Cement of Society: A study of social order. Cambridge (MA): Cambridge University Press. 
Falk, A., Fehr, E. and Fischbacher, U. (2005). Driving forces behind informal sanctions. Econometrica, 73 (6), 2017-2030.

- and Kosfeld, M. (2006). The hidden cost of control. American Economic Review, 96 (5), 1611-1630.

Farrington, D. P. and Welsh, B. (2006). Randomized experiments in criminology: What have we learned in the last two decades? Journal of Experimental Criminology, $1(1), 9-38$.

Fehr, E. and FAlK, A. (2002). Psychological foundations of incentives. European Economic Review, 46 (4-5), 687-724.

- and List, J. (2004). The hidden costs and returns of incentives - trust and trustworthiness among CEOs. Journal of the European Economic Association, 2 (5), 743-771.

Fischbacher, U. and GäChter, S. (2009). Social preferences, beliefs, and the dynamics of free riding in public good experiments. American Economic Review, forthcoming.

Fortin, B., Lacroix, G. and Villeval, M.-C. (2007). Tax evasion and social interactions. Journal of Public Economics, 91 (11-12), 2089-2112.

Frey, B. (1997). Not Just for Money. An Economic Theory of Personal Motivation. Cheltenham, UK: Edward Elgar Publishing.

— (2009). Punishment - and beyond, CESifo Working Paper No.2706.

- and MeIER, S. (2004). Social comparisons and pro-social behavior: Testing 'conditional cooperation' in a field experiment. American Economic Review, 94 (5), 17171722.

Galbiati, R. and Zanella, G. (2008). The social multiplier of tax evasion: Evidence from Italian audit data, Department of Economics, University of Siena, Working Paper 539.

Glaeser, E., Sacerdote, B. and Scheinkman, J. (1996). Crime and social interactions. Quarterly Journal of Economics, 111 (2), 507-548.

Gneezy, U. and Rustichini, A. (2000). A fine is a price. Journal of Legal Studies, 29 (1), 1-17.

Graetz, M. J., Reinganum, J. F. and Wilde, L. L. (1986). The tax compliance game: Toward an interactive theory of law enforcement. Journal of Law, Economics and Organization, 2, 1-32.

Harcourt, B. E. and Ludwig, J. (2006). Broken Windows: New Evidence from New York City and a Five-City Social Experiment. University of Chicago Law Review, 73 (1), 271-320.

Harrison, G. and List, J. (2004). Field experiments. Journal of Economic Literature, 42 (4), 1009-1055.

Head, S. W. (1985). World Broadcasting Systems: A Comparative Analysis. Belmont, California: Wadsworth. 
Hualmarsson, R. (2009). Crime and expected punishment: Changes in perceptions at the age of criminal majority. American Law and Economics Review, forthcoming.

Huck, S. and RAsul, I. (2009). Transaction costs in charitable giving: Evidence from two field experiments, Mimeo, University College London.

Jacob, B., Lefgren, L. and Moretti, E. (2007). The dynamics of criminal behavior: Evidence from weather shocks. Journal of Human Resources, 42 (3), 489-527.

Kahan, D. M. (1997). Social influence, social meaning, and deterrence. Virginia Law Review, 83 (2), 349-395.

Keizer, K., Lindenberg, S. and Steg, L. (2008). The spreading of disorder. Science, 322 (5908), 1681-1685.

Kessler, D. and Levitt, S. D. (1999). Using sentence enhancements to distinguish between deterrence and incapacitation. Journal of Law and Economics, 42, 343-363.

Kleven, H. J., Knudsen, M., Kreiner, C. T., Pedersen, S. and Saez, E. (2009). An experimental evaluation of the tax evasion and tax enforcement in Denmark, Mimeo, Department of Economics, University of Copenhagen.

LeViTt, S. D. (1998). Why do increased arrest rates appear to reduce crime: Deterrence, incapacitation, or measurement error? Economic Inquiry, 36 (3), 353-72.

- (2002). Using electoral cycles in police hiring to estimate the effects of police on crime: Reply. American Economic Review, 92 (4), 1244-1250.

- and List, J. A. (2007). What do laboratory experiments tell us about the real world? Journal of Economic Perspectives, 21 (2), 153-174.

— and - (2009). Field experiments in economics: The past, the present, and the future. European Economic Review, 53 (1), 1-18.

— and Miles, T. J. (2007). Empirical study of criminal punishment. pp. 455-495.

Lochner, L. (2007). Individual perceptions of the criminal justice system. American Economic Review, 97 (1), 444-460.

Manski, C. F. (2004). Measuring expectations. Econometrica, 72 (5), 1329-1376.

McAdams, R. H. and Rasmusen, E. B. (2007). Norms and the law. In A. M. Polinsky and S. Shavell (eds.), Handbook of Law and Economics, Volume 2, Amsterdam: North Holland, pp. 1573-1618.

McGraw, K. M. and Scholz, J. T. (1991). Appeals to civic virtue versus attention to self-interest: Effects on tax compliance. Law and Society Review, 25 (3), 471-498.

Meares, T. L., Katyal, N. and Kahan, D. M. (2004). Updating the study of punishment. Stanford Law Review, 56, 1171-1210.

NAGin, D. S. (1998). Criminal deterrence research at the outset of the twenty-first century. Crime and Justice, 23, 1-42. 
Newcomb, H. (2004). The Museum of Broadcast Communications Encyclopedia of Television. New York: Routledge, 2nd edn.

Open Society Institute (2005). Television across europe: Regulation, policy and independence. eu monitoring and advocacy program (eumap).

ORF Medienforschung (ed.) (2006). Ausstattung der Haushalte 1986-2006. Vienna.

Posner, E. A. (2000). Law and Social Norms. Cambridge: Harvard University Press.

Pruckner, G. J. and Sausgruber, R. (2008). Honesty on the Streets - A Natural Field Experiment on Newspaper Purchasing, Working Paper, University of Innsbruck.

Rincke, J. and Traxler, C. (2009). Deterrence through word of mouth, Max Planck Institute for Research on Collective Goods, Working Paper 2009-04.

SAH, R. K. (1991). Social osmosis and patterns of crime. Journal of Political Economy, 99 (6), 1272-1295.

Schwartz, R. D. and Orleans, S. (1967). On legal sanctions. University of Chicago Law Review, 34 (2), 274-300.

Shang, J. and Croson, R. (2007). Field experiments in charitable contribution: The impact of social influence on the voluntary provision of public goods. The Economic Journal, forthcoming.

Slemrod, J., Blumenthal, M. and Christian, C. (2001). Taxpayer response to an increased probability of audit: evidence from a controlled experiment in minnesota. Journal of Public Economics, 79 (3), 455-483.

Sunstein, C. R. (2004). Moral heuristics and moral framing. Minnesota Law Review, 88 (6), 1556-1597.

Traxler, C. and Winter, J. (2009). Survey evidence on conditional norm enforcement, Max Planck Institute for Research on Collective Goods, Working Paper 2009-03.

Wenzel, M. and TAYLOR, N. (2004). An experimental evaluation of tax-reporting schedules: a case of evidence-based tax administration. Journal of Public Economics, 88 (12), 2785-2799.

Wilson, J. Q. and Kelling, G. L. (1982). Broken windows. The Atlantic Monthly, 249 (3), 29-38. 


\section{Appendix I: Text and Layout of Mailings}

Note that the texts of all treatment manipulations were approved by GIS' legal department. Below we report the translated mailing texts and an original copy of a mailing that illustrates the layout.

\section{I.1 Standard Cover Letter (Control Treatment T1)}

Dear Mr. X,

You listen to radio, you watch TV? Then you are aware of the program variety offered by Austrian Public Broadcasting. The provision of these services, however, requires funding. Therefore, everybody who owns a radio or a $T V$ has to pay license fees. It is the task of GIS Gebühren Info Service GmbH to ensure that all $T V$ and radio consumers pay these fees.

Our data base does not show a registration of $T V$ or radio equipment at your address. This can have several reasons:

- We may have made a mistake in our data base and you are already registered at GIS. In this case, we apologize in advance.

- Your registration data may have changed, e.g., due to a move or a name change (marriage), and our computer system cannot match the data with your registration.

- You may not hold a radio or a TV at this address and therefore do not have to register anything.

- Maybe you have just forgotten to register your TV or radio.

We are legally obliged to clarify this issue and kindly ask you to answer our questions even if you have already registered at GIS. On the back of this letter you find a response form. Please fill in this form and send it back within the next 14 days.

We thank you for your cooperation. If you require further information, please call our service hotline at 0810001080 (Monday to Friday, 8.00 am to 9.00 pm, Saturday from $9.00 \mathrm{am}$ to $5.00 \mathrm{pm})$ or visit our web page at www.orf-gis.at. Kind regards, your GISTeam. 


\section{I.2 Legal Threat}

In the legal threat treatments (T2, T4 and T6), the cover letter includes the following paragraph at position [2] of the standard letter:

If you do not respond to this letter, a staff member of GIS will contact you in order to request information from you personally. If you refuse to provide information or if there is a well-founded suspicion that you provide disinformation, GIS is obligated to order an inquiry by the responsible federal authorities. Please keep in mind that in this case you may face legal consequences and considerable costs.

\section{I.3 Social Information}

In the social information mailings (treatments T3 and T4), we add the following paragraph at position [1] of the standard letter:

Do you actually know that almost all citizens comply with this legal duty? In fact, 94 percent - a vast majority of all households - have registered their broadcasting receivers.

\section{I.4 Moral Appeal}

The treatments with a moral appeal (T5 and T6), included the following paragraph at position [1]:

Those who do not conscientiously register their broadcasting receivers not only violate the law, but also harm all honest households. Hence, registering is also a matter of fairness. 


\section{I.5 Original Copy}
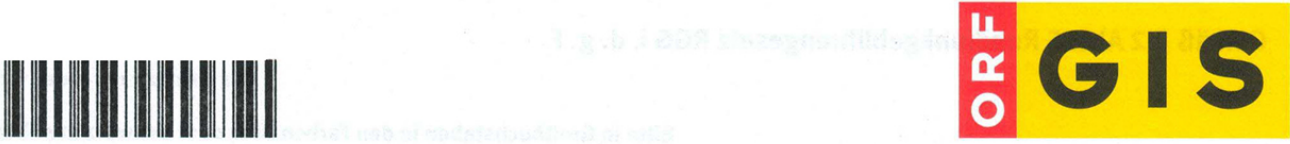

GIS GMBH, 1051 Wien, Postfach 1999, DMMD211 60125200

GEBUHREN INFO SERVICE

Frau

60125200

DMMD211

Wien, 3. Oktober 2005

\section{SIE HÖREN RADIO, SIE SEHEN FERN?}

Sehr geehrte Frau

Sie hören Radio, Sie sehen fern? Dann kennen Sie die vielfältigen Programme, die Ihnen der ORF täglich bietet. Diese Leistungen kosten Geld. Aufgabe der GIS Gebühren Info Service GmbH ist es, dafür zu sorgen, dass alle Konsumenten von Radio und Fernsehen Gebühren zahlen. Denn sobald man ein Rundfunkempfangsgerät besitzt, sind Gebühren zu bezahlen.

Wissen Sie übrigens, dass beinahe alle Bürger dieser gesetzlichen Verpflichtung nachkommen? Es sind 94 Prozent, also eine überwältigende Mehrheit aller Haushalte, die ihre Rundfunkempfangsgeräte gemeldet haben.

Unter Ihrer Anschrift finden wir keine Meldung von Rundfunkempfangsgeräten in unserer Datenbank. Das kann verschiedene Gründe haben:

- Vielleicht ist uns ein Fehler in der Datenverwaltung unterlaufen und wir dürfen Sie bereits zu unseren Kunden zählen. In diesem Fall bitten wir schon jetzt um Entschuldigung!

- Vielleicht haben sich Ihre Kundendaten geändert, etwa durch Übersiedlung oder Namensänderung (Heirat), und unsere EDV kann Ihre Daten nicht zuordnen.

- Vielleicht haben Sie keine Rundfunkempfangseinrichtungen unter dieser Adresse und sind daher auch nicht meldepflichtig.

- Vielleicht haben Sie aber einfach nur vergessen, Ihre Geräte anzumelden.

Wir sind von Gesetz wegen verpflichtet nachzufragen und bitten Sie deshalb, unsere Fragen zu beantworten in jedem Fall, auch wenn Sie bereits Kunde sind. Eine Rückantwort ist auf der Rückseite dieses Schreibens vorbereitet. Bitte füllen Sie diese aus und schicken Sie den Bogen innerhalb von 14 Tagen im Antwortkuvert an uns zurück.

Sollten Sie auf dieses Schreiben nicht reagieren, wird Sie demnächst ein Mitarbeiter der GIS kontaktieren um eine persönliche Auskunft zu erhalten. Verweigern Sie diese oder besteht der begründete Verdacht, dass Sie eine falsche Auskunft erteilt haben, hat die GIS eine Überprüfung der Gebührenpflicht seitens der zuständigen Bundesverwaltungsbehörde zu veranlassen. Bedenken Sie bitte, dass Ihnen in diesem Fall rechtliche Konsequenzen sowie erhebliche finanzielle Kosten entstehen können.

Wir danken Ihnen für Ihre Mithilfe. Wenn Sie weitere Informationen wünschen, können Sie uns unter der Service-Hotline $\mathbf{0 8 1 0} \mathbf{0 0} \mathbf{1 0} \mathbf{8 0}$ (Montag bis Freitag von 8.00 bis $21.00 \mathrm{Uhr}$, Samstag von 9.00 bis $17.00 \mathrm{Uhr}$ ) anrufen oder uns im Internet besuchen: www.orf-gis.at.

Mit freundlichen Grüßen

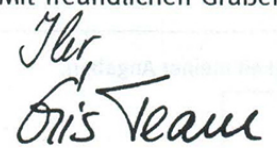

GIS GEBÜHREN INFO SERVICE GMBH

1051 Wien, Postfach 1999 • Service-Hotline: 0810001080 • E-Mail: gis.office@orf-gis.at • Internet: www.orf-gis.at

DVR 0997285 - Sitz: Wien, Österreich • PSK Konto Nr. 7503 146, BLZ $60000 \bullet$ Fbg: Handelsgericht Wien • Firmenbuch Nr. 174754

Figure A.1: Original mailing for treatment T4 (Info $\times$ Threat) 


\section{Appendix II: Summary Statistics on Municipality Characteristics}

Table A.1: Municipality control variables

\begin{tabular}{|c|c|c|c|c|c|}
\hline Variable & Description & Mean & SD & Min & Max \\
\hline PopSize & population size & $43,085.37$ & $74,649.49$ & 62.00 & $240,278.00$ \\
\hline PopDensity & inhabitants/ha & 8.52 & 23.84 & 0.01 & 256.30 \\
\hline Compliance & compliance rate in 2005 & 93.51 & 5.87 & 58.24 & $143.54^{*}$ \\
\hline Mailing Coverage & mailings relative to PopSize & 0.06 & 0.06 & 0.00 & 0.20 \\
\hline AvIncome & average income/year in $€$ & $20,863.45$ & 2150.70 & $17,497.13$ & $36,105.19$ \\
\hline AvEducation & average years of education & 11.17 & 0.47 & 9.72 & 13.23 \\
\hline AvAge & average age of inhabitants in years & 48.03 & 1.18 & 42.81 & 54.18 \\
\hline Unemployed & unemployment rate & 3.14 & 1.67 & 0 & 16.96 \\
\hline Migration & $\%$ of population inflow from moving & 5.26 & 3.14 & 0.39 & 31.70 \\
\hline Foreign & $\%$ of non-Austrian nationalities & 9.37 & 5.44 & 0 & 50.32 \\
\hline VoteLeft & $\%$ of votes for left parties ${ }^{* *}$ & 11.80 & 5.23 & 0 & 37.23 \\
\hline VoteCenterLeft & $\%$ of votes for center-left party & 27.07 & 12.33 & 2.00 & 78.41 \\
\hline VoteRight & $\%$ of votes for right parties & 18.53 & 5.56 & 4.00 & 46.00 \\
\hline StudentShare & $\%$ of students & 1.84 & 1.16 & 0 & 6.67 \\
\hline HomeOwner & $\%$ of home owners & 57.85 & 19.80 & 10.06 & 98.27 \\
\hline FamMarried & $\%$ of married households & 42.78 & 2.73 & 31.67 & 54.16 \\
\hline FamDiv & $\%$ of divorced and widowed households & 11.55 & 4.10 & 3.78 & 20.42 \\
\hline CathShare & $\%$ of Roman Catholics & 80.83 & 14.49 & 20.06 & 99.90 \\
\hline OrthShare & $\%$ of Catholic Orthodox & 1.48 & 1.75 & 0 & 11.37 \\
\hline Sample & 41,007 (delivered mailings) & & & & \\
\hline
\end{tabular}

Notes: * Compliance rates above $100 \%$ are due to municipalities where households have registered their TVs but no longer live there (many households do not unregister license fees after moving, but continue to pay fees under their old address). ${ }^{* *}$ Vote shares are in percentage of the electorate rather than casted votes.

\section{Appendix III: Response Time}

Figure A.2 compares the relative as well as the cumulated frequencies of registrations (A-responses) per week between the baseline treatment (T1) and the threat (T2), socialinformation (T3), and the moral-appeal (T5) treatments, respectively. The figure shows that the threat increases registrations particularly in the first two weeks after sending the mailings (upper left panel); within this period, the other two treatments show hardly any difference to the baseline. The average response time in the threat treatments is 22.1 days (23.7 in the treatments without a threat). In the moral appeal, we observe an average of 24.4 days.

Recall that the mailings request recipients to respond within two weeks. We therefore estimated the treatments' impact on A-responses within this period (using estimations equivalent to those from section 5.2.1). The findings are similar to the results presented in the main text. The legal threat increases registrations within the first two weeks by nearly $20 \%$. While the social information has no significant effect, we find a highly significant effect of the moral appeal. The treatment reduces response by $18 \%$ as compared to the neutrally framed mailing. As indicated in the lower panel of figure A.2, the gap to the 

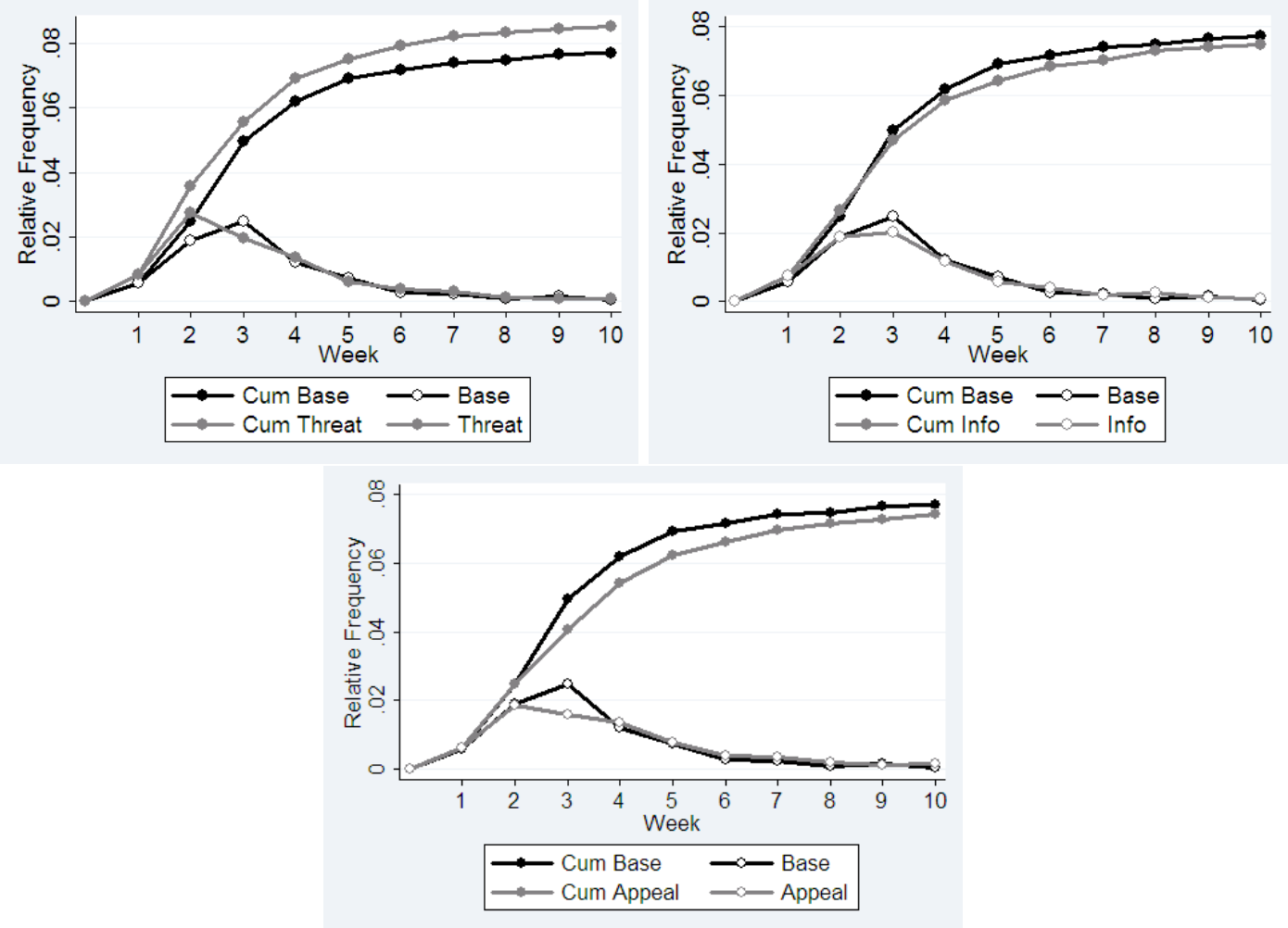

Figure A.2: Time pattern of A-Responses (registrations): base vs. legal threat (top left), base vs. social information (top right), and base vs. moral appeal

base treatment starts to decline with week four. Therefore, we do not find a significantly negative effect of the moral appeal when we focus on the response within 50 days (or more). 


\section{Appendix IV: Type Heterogeneity}

Let us denote the share of evaders (A-types) and law-abiding persons (B-types) in our sample by $s^{A}$ and $s^{B}$, respectively. The fraction of those without TV or radio (C-types) is $1-s^{A}-s^{B}$. Given the type specific response options discussed in Section 3.2, we know that response in category A and B reveals the respondents' type. ${ }^{35}$ The observed frequency of registrations in treatment $j \in\{1, \ldots, 6\}, p_{j}^{A}$, can be expressed as

$$
p_{j}^{A}=s_{a} r_{j}(A \mid a)
$$

the registration frequency among A-types, $r_{j}(A \mid a)$, weighted with the share of evaders (A-types) in the sample. Equivalently, the observed frequency of update-responses in treatment $j$ corresponds to

$$
p_{j}^{B}=s_{b} r_{j}(B \mid b),
$$

the frequency of B-responses among B-types, $r_{j}(B \mid b)$, weighted with the share of these types in the sample.

The precise type distribution is unobserved and cannot be identified from our data. Consequently, we cannot obtain point estimates of the type-specific treatment response, $r_{j}(A \mid a)$ and $r_{j}(B \mid b)$. Due to randomization, however, the types' frequencies will not systematically differ between the treatments. This is why we have implicitly assumed $s_{a j}=s_{a}$ and $s_{b j}=s_{b}$ for all $j$. Any significant differences in our observed response rates $p_{j}^{A}$ and $p_{j}^{B}$ must therefore reflect differences in the treatments' impact on $r_{j}(A \mid a)$ and $r_{j}(B \mid b)$, respectively.

The implications of the type heterogeneity for the quantitative interpretation of the treatment differences are straightforward. The data clearly reveal that $s_{a}<1$ and $s_{b}<1$. The comparison of $p_{j}^{A}$ (respectively $p_{j}^{B}$ ) between treatments will therefore underestimate the differences in the type-specific response rates. To illustrate this point, consider the outcome of the experiment as illustrated in table 4. Comparing T1 and T2, we find that the legal threat raises the registration rate by about one percentage point, from $p_{1}^{A}=0.0862$ to $p_{2}^{A}=0.0967$. On average, however, $28 \%$ of the individuals identify themselves as B-types (see table 4). It follows that $s_{a} \leq 0.72$, which implies that the difference between $r_{1}^{A}$ and $r_{2}^{A}$ will be at least 1.5 percentage points $\left(\left(p_{2}^{A}-p_{1}^{A}\right) / 0.72\right)$. Note also that the estimations presented in sections 5 neglects $s_{a}<1$ and $s_{b}<1$. The estimated coefficients provide lower bounds for the treatment effects on the type-specific response.

\footnotetext{
${ }^{35}$ That is, only A-types can make an A-response (registration) and only B-types can produce a B-response (updating of information with a verified registration ID).
} 


\section{Appendix V: Details on the Manipulation Check}

The manipulation check was implemented November 24-28, 2008, using the online survey tool unipark.de. Survey participants were invited via email over the University of Innsbruck mailing list. To provide an incentive for participating, everybody who finished the survey had a $1 / 25$ chance of winning an Amazon voucher worth $€ 25$. 4,165 individuals clicked on the link to the survey and 3,233 completed the survey within an average of 8 minutes.

The question regarding the perceived risk of an inspection was formulated as follows: "How large do you think is the risk - after having received this mailing [omitted for the control group (T0)] - that the person will receive a 'visit' by a licensing inspector within the next 4 weeks? Please tick a number on the scale between 0 (very unlikely) to 100 (very likely)."

We also asked for the expected fines in case of a detection:

"Assume that the person is indeed detected by a field inspector. Which consequences do you expect? He has to pay...

(1) no fine.

(2) a fine of less than $€ 100$.

(3) a fine of $€ 100-500$.

(4) a fine of $€ 500-1000$.

(5) a fine of $€ 1000-2000$.

(6) a fine of $€ 2000-4000$.

(7) a fine of more than $€ 4000$."

Expectations regarding social sanctions were elicited in the following way:

"An acquaintance of the person learns that he has not payed TV license fees for the past 6 months. [in the B-type vignette: ...that he has not informed GIS about his change in the address.] How will the acquaintance react?

(1) will strongly approve the behavior, and support him not to register for license fees [not to update the information].

(2) will approve the behavior.

(3) will not react at all.

(4) will disapprove the behavior.

(5) will strongly disapprove the behavior, and cool down the contact to the person. 


\section{University of Innsbruck - Working Papers in Economics and Statistics Recent papers}

2009-25 Rupert Sausgruber and Jean-Robert Tyran: Tax Salience, Voting, and Deliberation

2009-24 Gerald J. Pruckner and Rupert Sausgruber: Honesty on the Streets - A Natural Field Experiment on Newspaper Purchasing

2009-23 Gerlinde Fellner, Rupert Sausgruber and Christian Traxler: Testing Enforcement Strategies in the Field: Legal Threat, Moral Appeal and Social Information

2009-22 Ralph-C. Bayer, Elke Renner and Rupert Sausgruber: Confusion and Reinforcement Learning in Experimental Public Goods Games

2009-21 Sven P. Jost: Transfer Pricing Risk Awareness of Multinational Corporations Evidence from a Global Survey

2009-20 Andrea M. Leiter and Engelbert Theurl: The Convergence of Health Care Financing Structures: Empirical Evidence from OECD-Countries

2009-19 Francesco Feri and Miguel A.Meléndez-Jiménez: Coordination in Evolving Networks with Endogenous Decay

2009-18 Harald Oberhofer: Firm growth, European industry dynamics and domestic business cycles

2009-17 Jesus Crespo Cuaresma and Martin Feldkircher: Spatial Filtering, Model Uncertainty and the Speed of Income Convergence in Europe

2009-16 Paul A. Raschky and Manijeh Schwindt: On the Channel and Type of International Disaster Aid

2009-15 Jianying Qiu: Loss aversion and mental accounting: The favorite-longshot bias in parimutuel betting

2009-14 Siegfried Berninghaus, Werner Güth, M. Vittoria Levati and Jianying Qiu: Satisficing in sales competition: experimental evidence

2009-13 Tobias Bruenner, Rene Levinský and Jianying Qiu: Skewness preferences and asset selection: An experimental study

2009-12 Jianying Qiu and Prashanth Mahagaonkar: Testing the Modigliani-Miller theorem directly in the lab: a general equilibrium approach

2009-11 Jianying Qiu and Eva-Maria Steiger: Understanding Risk Attitudes in two Dimensions: An Experimental Analysis

2009-10 Erwann Michel-Kerjan, Paul A. Raschky and Howard C. Kunreuther: Corporate Demand for Insurance: An Empirical Analysis of the U.S. Market for Catastrophe and Non-Catastrophe Risks

2009-09 Fredrik Carlsson, Peter Martinsson, Ping Qin and Matthias Sutter: Household decision making and the influence of spouses' income, education, and communist party membership: A field experiment in rural China

2009-08 Matthias Sutter, Peter Lindner and Daniela Platsch: Social norms, thirdparty observation and third-party reward

2009-07 Michael Pfaffermayr: Spatial Convergence of Regions Revisited: A Spatial Maximum Likelihood Systems Approach

2009-06 Reimund Schwarze and Gert G. Wagner: Natural Hazards Insurance in Europe - Tailored Responses to Climate Change Needed

2009-05 Robert Jiro Netzer and Matthias Sutter: Intercultural trust. An experiment in Austria and Japan

2009-04 Andrea M. Leiter, Arno Parolini and Hannes Winner: Environmental Regulation and Investment: Evidence from European Industries

2009-03 Uwe Dulleck, Rudolf Kerschbamer and Matthias Sutter: The Economics of Credence Goods: On the Role of Liability, Verifiability, Reputation and Competition

2009-02 Harald Oberhofer and Michael Pfaffermayr: Fractional Response Models A Replication Exercise of Papke and Wooldridge (1996) 
2009-01 Loukas Balafoutas: How do third parties matter? Theory and evidence in a dynamic psychological game.

2008-27 Matthias Sutter, Ronald Bosman, Martin Kocher and Frans van Winden: Gender pairing and bargaining - Beware the same sex! Revised version published in Experimental Economics, Vol. 12 (2009): 318-331.

2008-26 Jesus Crespo Cuaresma, Gernot Doppelhofer and Martin Feldkircher: The Determinants of Economic Growth in European Regions.

2008-25 Maria Fernanda Rivas and Matthias Sutter: The dos and don'ts of leadership in sequential public goods experiments.

2008-24 Jesus Crespo Cuaresma, Harald Oberhofer and Paul Raschky: Oil and the duration of dictatorships.

2008-23 Matthias Sutter: Individual behavior and group membership: Comment. Revised Version forthcoming in American Economic Review.

2008-22 Francesco Feri, Bernd Irlenbusch and Matthias Sutter: Efficiency Gains from Team-Based Coordination - Large-Scale Experimental Evidence. Revised and extended version forthcoming in American Economic Review.

2008-21 Francesco Feri, Miguel A. Meléndez-Jiménez, Giovanni Ponti and Fernando Vega Redondo: Error Cascades in Observational Learning: An Experiment on the Chinos Game.

2008-20 Matthias Sutter, Jürgen Huber and Michael Kirchler: Bubbles and information: An experiment.

2008-19 Michael Kirchler: Curse of Mediocrity - On the Value of Asymmetric Fundamental Information in Asset Markets.

2008-18 Jürgen Huber and Michael Kirchler: Corporate Campaign Contributions as a Predictor for Abnormal Stock Returns after Presidential Elections.

2008-17 Wolfgang Brunauer, Stefan Lang, Peter Wechselberger and Sven Bienert: Additive Hedonic Regression Models with Spatial Scaling Factors: An Application for Rents in Vienna.

2008-16 Harald Oberhofer, Tassilo Philippovich: Distance Matters! Evidence from Professional Team Sports.

2008-15 Maria Fernanda Rivas and Matthias Sutter: Wage dispersion and workers' effort.

2008-14 Stefan Borsky and Paul A. Raschky: Estimating the Option Value of Exercising Risk-taking Behavior with the Hedonic Market Approach. Revised version forthcoming in Kyklos.

2008-13 Sergio Currarini and Francesco Feri: Information Sharing Networks in Oligopoly.

2008-12 Andrea M. Leiter: Age effects in monetary valuation of mortality risks - The relevance of individual risk exposure.

2008-11 Andrea M. Leiter and Gerald J. Pruckner: Dying in an Avalanche: Current Risks and their Valuation.

2008-10 Harald Oberhofer and Michael Pfaffermayr: Firm Growth in Multinational Corporate Groups.

2008-09 Michael Pfaffermayr, Matthias Stöckl and Hannes Winner: Capital Structure, Corporate Taxation and Firm Age.

2008-08 Jesus Crespo Cuaresma and Andreas Breitenfellner: Crude Oil Prices and the Euro-Dollar Exchange Rate: A Forecasting Exercise.

2008-07 Matthias Sutter, Stefan Haigner and Martin Kocher: Choosing the carrot or the stick? - Endogenous institutional choice in social dilemma situations.

2008-06 Paul A. Raschky and Manijeh Schwindt: Aid, Catastrophes and the Samaritan's Dilemma.

2008-05 Marcela Ibanez, Simon Czermak and Matthias Sutter: Searching for a better deal - On the influence of group decision making, time pressure and gender in a search experiment. Revised version published in Journal of Economic Psychology, Vol. 30 (2009): 1-10. 
2008-04 Martin G. Kocher, Ganna Pogrebna and Matthias Sutter: The Determinants of Managerial Decisions Under Risk.

2008-03 Jesus Crespo Cuaresma and Tomas Slacik: On the determinants of currency crises: The role of model uncertainty. Revised version accepted for publication in Journal of Macroeconomics)

2008-02 Francesco Feri: Information, Social Mobility and the Demand for Redistribution.

2008-01 Gerlinde Fellner and Matthias Sutter: Causes, consequences, and cures of myopic loss aversion - An experimental investigation. Revised version published in The Economic Journal, Vol. 119 (2009), 900-916.

2007-31 Andreas Exenberger and Simon Hartmann: The Dark Side of Globalization. The Vicious Cycle of Exploitation from World Market Integration: Lesson from the Congo.

2007-30 Andrea M. Leiter and Gerald J. Pruckner: Proportionality of willingness to pay to small changes in risk - The impact of attitudinal factors in scope tests. Revised version forthcoming in Environmental and Resource Economics.

2007-29 Paul Raschky and Hannelore Weck-Hannemann: Who is going to save us now? Bureaucrats, Politicians and Risky Tasks.

2007-28 Harald Oberhofer and Michael Pfaffermayr: FDI versus Exports. Substitutes or Complements? A Three Nation Model and Empirical Evidence.

2007-27 Peter Wechselberger, Stefan Lang and Winfried J. Steiner: Additive models with random scaling factors: applications to modeling price response functions.

2007-26 Matthias Sutter: Deception through telling the truth?! Experimental evidence from individuals and teams. Revised version published in The Economic Journal, Vol. 119 (2009), 47-60.

2007-25 Andrea M. Leiter, Harald Oberhofer and Paul A. Raschky: Productive disasters? Evidence from European firm level data. Revised version forthcoming in Environmental and Resource Economics.

2007-24 Jesus Crespo Cuaresma: Forecasting euro exchange rates: How much does model averaging help?

2007-23 Matthias Sutter, Martin Kocher and Sabine Strauß: Individuals and teams in UMTS-license auctions. Revised version with new title "Individuals and teams in auctions" published in Oxford Economic Papers, Vol. 61 (2009): 380394).

2007-22 Jesus Crespo Cuaresma, Adusei Jumah and Sohbet Karbuz: Modelling and Forecasting Oil Prices: The Role of Asymmetric Cycles. Revised version accepted for publication in The Energy Journal.

2007-21 Uwe Dulleck and Rudolf Kerschbamer: Experts vs. discounters: Consumer free riding and experts withholding advice in markets for credence goods. Revised version published in International Journal of Industrial Organization, Vol. 27, Issue 1 (2009): 15-23.

2007-20 Christiane Schwieren and Matthias Sutter: Trust in cooperation or ability? An experimental study on gender differences. Revised version published in Economics Letters, Vol. 99 (2008): 494-497.

2007-19 Matthias Sutter and Christina Strassmair: Communication, cooperation and collusion in team tournaments - An experimental study. Revised version published in: Games and Economic Behavior, Vol.66 (2009), 506-525.

2007-18 Michael Hanke, Jürgen Huber, Michael Kirchler and Matthias Sutter: The economic consequences of a Tobin-tax - An experimental analysis.

2007-17 Michael Pfaffermayr: Conditional beta- and sigma-convergence in space: A maximum likelihood approach. Revised version forthcoming in Regional Science and Urban Economics.

2007-16 Anita Gantner: Bargaining, search, and outside options. Published in: Games and Economic Behavior, Vol. 62 (2008), pp. 417-435. 
2007-15 Sergio Currarini and Francesco Feri: Bilateral information sharing in oligopoly.

2007-14 Francesco Feri: Network formation with endogenous decay.

2007-13 James B. Davies, Martin Kocher and Matthias Sutter: Economics research in Canada: A long-run assessment of journal publications. Revised version published in: Canadian Journal of Economics, Vol. 41 (2008), 22-45.

2007-12 Wolfgang Luhan, Martin Kocher and Matthias Sutter: Group polarization in the team dictator game reconsidered. Revised version published in: Experimental Economics, Vol. 12 (2009), 26-41.

2007-11 Onno Hoffmeister and Reimund Schwarze: The winding road to industrial safety. Evidence on the effects of environmental liability on accident prevention in Germany.

2007-10 Jesus Crespo Cuaresma and Tomas Slacik: An "almost-too-late" warning mechanism for currency crises. (Revised version accepted for publication in Economics of Transition)

2007-09 Jesus Crespo Cuaresma, Neil Foster and Johann Scharler: Barriers to technology adoption, international R\&D spillovers and growth.

2007-08 Andreas Brezger and Stefan Lang: Simultaneous probability statements for Bayesian P-splines.

2007-07 Georg Meran and Reimund Schwarze: Can minimum prices assure the quality of professional services?.

2007-06 Michal Brzoza-Brzezina and Jesus Crespo Cuaresma: Mr. Wicksell and the global economy: What drives real interest rates?.

2007-05 Paul Raschky: Estimating the effects of risk transfer mechanisms against floods in Europe and U.S.A.: A dynamic panel approach.

2007-04 Paul Raschky and Hannelore Weck-Hannemann: Charity hazard - A real hazard to natural disaster insurance. Revised version forthcoming in: Environmental Hazards.

2007-03 Paul Raschky: The overprotective parent - Bureaucratic agencies and natural hazard management.

2007-02 Martin Kocher, Todd Cherry, Stephan Kroll, Robert J. Netzer and Matthias Sutter: Conditional cooperation on three continents. Revised version published in: Economics Letters, Vol. 101 (2008): 175-178.

2007-01 Martin Kocher, Matthias Sutter and Florian Wakolbinger: The impact of naïve advice and observational learning in beauty-contest games. 


\title{
University of Innsbruck
}

\section{Working Papers in Economics and Statistics}

$2009-23$

Gerlinde Fellner, Rupert Sausgruber and Christian Traxler

Testing Enforcement Strategies in the Field: Legal Threat, Moral Appeal and Social Information

\begin{abstract}
We run a large-scale natural field experiment to evaluate alternative strategies to enforce compliance with the law. The experiment varies the text of mailings sent to potential evaders of TV license fees. We find a strong alert effect of mailings, leading to a substantial increase in compliance. Among different mailing conditions a legal threat that stresses a high detection risk has a significant and highly robust deterrent effect. Neither appealing to morals nor imparting information about others' behavior enhances compliance. However, the information condition has a positive effect in municipalities where evasion is believed to be common. Overall, the economic model of crime performs remarkably well in explaining our data.
\end{abstract}

ISSN 1993-4378 (Print)

ISSN 1993-6885 (Online) 